\title{
Three Dimensions of Transformative Impact and Capacity: A Conceptual Framework Applied in Social Innovation Practice
}

\author{
Tim Strasser ${ }^{1, *}$, Joop de Kraker ${ }^{1,2}$ and René Kemp ${ }^{1,3}$ \\ 1 Maastricht Sustainability Institute, Maastricht University, 6211 ME Maastricht, The Netherlands; \\ j.dekraker@maastrichtuniversity.nl or joop.dekraker@ou.nl (J.d.K.); r.kemp@maastrichtuniversity.nl (R.K.) \\ 2 Department of Environmental Sciences, Open University, 6419 AT Heerlen, The Netherlands \\ 3 United Nations University-Maastricht Economic and Social Research Institute on Innovation and \\ Technology (UNU-MERIT), United Nations University, 6211 AX Maastricht, The Netherlands \\ * Correspondence: tim.strasser@maastrichtuniversity.nl; Tel.: +31-684-817-636
}

Received: 31 March 2020; Accepted: 4 June 2020; Published: 10 June 2020

\begin{abstract}
This article empirically applies, tests, and refines a conceptual framework that articulates three dimensions of transformative impact and transformative capacity: depth, width, and length. This responds to the need for a more precise conceptual language to describe these terms and operationalize them in a way that is useful for practitioners in social innovation networks. By applying this framework in diverse cases of social innovation networks, we demonstrate how the framework can serve to identify and assess transformative impacts and the capacities needed to bring about these impacts. Our findings include 1. empirical substantiations, 2. refinements, and 3. interaction effects among the elements of the framework. We also subjected the framework to an appraisal by practitioners in social innovation networks regarding the recognizability of the framework elements and usefulness for practice. The framework was generally perceived as very meaningful and valuable for social innovation practitioners as a way to understand, assess, strategically design and evaluate their transformation efforts. Drawing on feedback by practitioners, we offer recommendations for further research and development of the framework to improve its usefulness in practice.
\end{abstract}

Keywords: transformative impact; transformative capacity; social innovation; impact assessment

\section{Introduction}

Despite the rising urgency of societal challenges like climate change, biodiversity loss, social inequality, and economic instability, status quo oriented socio-economic development continues largely unaltered and incremental policy changes predominate [1-4]. While recent growth in grassroots movements are becoming harder to ignore, calls for more fundamental change can increasingly be heard also from mainstream institutions like the Intergovernmental Panel on Climate Change (IPCC) [5], and the Intergovernmental Science-Policy Platform on Biodiversity and Ecosystem Services (IPBES) [6,7]. The potential of social innovation to challenge and transform established institutions more fundamentally has gained attention from policy actors [8]. Yet, recent research on the dynamics of transformative social innovation [9] points to the ambiguous character of innovation in terms of its potential to both reproduce and transform the status quo [10-12]. While existing research focuses mostly on describing dynamics of how social innovation can develop, spread, and interact with established institutions [13], little research exists about ways to identify and assess transformative impact, as well as the capacities required for social innovation efforts to become transformative.

Building on the recent Transformative Social Innovation (TSI) theory $[9,14,15]$, we previously developed a conceptual framework and research agenda [16] for better understanding transformative 
impact and transformative capacity in a way that is meaningful in practice. In our conceptual framework we articulated three institutional dimensions as categories for defining transformative impact and capacity: depth, width, and length. This builds on similar typologies [13] of how social innovations can grow, diffuse, or scale, while operationalizing the elements in more concrete and practice-oriented terms. For each of these three dimensions, we described constituting elements of transformative impact as well as the capacities needed for social innovators to realize such impact. In the remainder of this article we refer to this as the 3D framework (summarized in the next section). The 3D framework [16] has so far been rather hypothetical, as an attempt to reformulate key issues in TSI theory in practice relevant terms. Hence, the intention of this article is to further develop this framework in ways that make it more analytically rigorous, empirically-based, and connected to everyday reality and needs of practitioners.

The purpose of this article is two-fold: firstly, to apply the 3D framework in different case contexts, so as to identify empirical examples that substantiate the framework elements and to refine these elements where needed. This makes the 3D framework more understandable and useful in practice. That is, concrete examples help to understand what the framework elements mean concretely, which issues are important to consider, and why. This can guide operationalization of the 3D framework for use by practitioners and researchers interested in studying and supporting diverse kinds of social innovation actors. Performing a rigorous, in-depth assessment or comparative analysis of the cases is considered beyond the scope of this article. Secondly, we aim to test the 3D framework in practice, in terms of its recognizability (how does it resonate?) and usefulness for practitioners (is it practically meaningful?). This article therefore addresses the following two research questions:

- RQ1: How can the 3D framework serve to identify and assess transformative impact and the required transformative capacity in empirical cases of social innovation?

- RQ2: To what extent and in which way is the 3D framework perceived as recognizable and useful by practitioners?

Different ways of applying the 3D framework are explored to test how it could be made useful in practice. We see this as an important step towards operationalizing the 3D framework in the form of a practice tool to support efforts of capacity building and impact achievement. Some possible applications of the 3D framework include using it for impact assessment, strategy development, design of interventions, internal reflection, monitoring, and evaluation.

The article is structured in the following way: in Section 2 we summarize the 3D framework [16] and how it builds on related literature. In Section 3 we describe the methodology and empirical cases that serve for applying and testing the framework. Section 4 presents the results of this study, which consist of the substantiating examples and refinements of the 3D framework, as well as practitioner responses about how the framework was perceived as recognizable and useful in practice. In Section 5 we discuss our findings in light of our research questions and their significance for theory and practice, reflect on the limitations of this study, and provide recommendations for future research.

\section{Three Dimensions of Transformative Change, Impact, and Capacity}

Transformative change is a conceptually contested term, defined from many theoretical lenses [17]. Different aspects of transformative change are pertinent to mention (though we do not address these in detail): what it is (not), why and when it is needed, how it can come about, and how to know if it occurred. In this section we summarize the 3D framework of transformative impact and capacity and briefly discuss how it connects to these considerations and related literature (for more details, see our original explanation of the 3D framework [16]).

The 3D framework [16] articulates three dimensions of institutional change as a way to make more specific the types and degrees of transformative impact and the capacities required to realize such impact. This was developed in response to the need for 1 . a conceptual language for describing degrees of depth, diffusion and stability in the developing theory of Transformative Social Innovation (TSI) that 
is "recognizable and useful in policy and practice" (p. 169) and 2. empowering heuristics and theories of change to inform strategies of practitioners (p. 20) [18]. From an institutional perspective, TSI theory proposes that the unique characteristic of transformative change, as opposed to non-transformative change, is that it involves "challenging, altering, or replacing dominant institutions" [9]. However, this is still rather imprecise as to how fundamentally, at which scale, and how persistently dominant institutions are being challenged, altered, or replaced. We proposed [16] that the notion of "degrees of institutionalization" [18] (p. 18) along depth, width, and length dimensions can allow for a more precise conceptualization of transformative change, in a way that can be recognizable and useful in practice.

The three dimensions can be used to describe how deeply, widely, and persistently institutionalized dominant institutions are, as well as the institutional changes or creation of alternative institutions that social innovators seek to achieve. The transformation of society into a market society [19] is an example of a deep change, which continues to be influential at the global level in a way that is coherently adaptive to diverse cultural contexts. While transformative change is oftentimes glorified as the most important or desirable type of change (especially among those seeking to bring it about), this is not necessarily the case for everyone or every situation. It is one type of change among many others that may be more appropriate in certain situations or contexts, while other types of change (e.g., incremental change) are equally or more appropriate in other situations [20]. The 3D framework helps to be more explicit and intentional about the kind of change sought, i.e., the degree of depth, width, and length at which actors seek to intervene. The three institutional dimensions are briefly summarized in Table 1, based on our original framework [16]. See Figure 1 for a graphic representation, emphasizing the degrees of institutionalization for each dimension.

Transformative changes and impacts can thus be assessed by identifying to what degree and in which way changes have been realized across each of these three dimensions. Often this can only be done in hindsight [13]. Assessing impacts is more concrete than assessing transformative change in general, as impact focuses on how the interventions of particular actors have caused or contributed to transformative change. In the context of social innovation, the three dimensions can be used to assess how deeply embedded (depth), widely influential (width), and persistently reproduced (length) the institutional changes promoted by social innovators have become and to what extent they have challenged, altered, or replaced dominant institutions in relation to these three dimensions [16]. Given the complexity of this kind of change, it is very difficult to identify causal attribution to individual actors or actions. Transformation is co-produced through highly dispersed agency [22] of many actors and complex interactions with wider and longer-term societal and environmental factors. We prefer to speak of contributions of actors to transformative change that in some cases may be more easily identified or more straight-forward to attribute than in others.

How to actually bring about transformative impact is a critical question: especially for social innovators aiming for transformation, as well as researchers seeking to understand or policy-makers seeking to support enabling conditions. We define transformative capacity as "the ability to turn transformative potential into transformative impact." [16] (p. 7). This involves a range of capacities among not only individuals but also collectives of social innovation actors who are connected via trans-local networks [23]. By synthesizing results from the TRANSIT project (TRANsformative Social Innovation Theory-www.transitsocialinnovation.eu) on TSI theory [14,24], we distilled twelve transformative capacities: four for each of the three institutional dimensions. These are presented in Figure 2 and are not further elaborated here, as they are described in detail in our original framework [16] (conceptually) and the rest of this article (empirically). By testing the conceptual framework in practice, some of these capacities have been revised or complemented by additional ones (see Sections 4 and 5). 
Table 1. Summary of three institutional dimensions.

\begin{tabular}{ll}
\hline & $\begin{array}{l}\text { Depth refers to how deeply ways of doing, organizing, framing, } \\
\text { and knowing (DOFK) are embedded in formal structures like } \\
\text { policies, incentive mechanisms, legal codes, as well as cultural } \\
\text { values, mental models, and worldviews. Social change can take } \\
\text { place at different degrees of depth, in terms of incremental, } \\
\text { reformative, or transformative change [20,21]. Transformation is } \\
\text { the most fundamental type of change, where deeply embedded } \\
\text { rules or assumptions are changed. }\end{array}$ \\
& $\begin{array}{l}\text { Width refers to how widely influential ways of doing, } \\
\text { organizing, framing, and knowing (DOFK) are across different } \\
\text { geographic and cultural contexts, or societal sub-sectors, }\end{array}$ \\
$\begin{array}{l}\text { where core characteristics are coherent despite contextual } \\
\text { differences. Transformation can take place at different levels of }\end{array}$ \\
$\begin{array}{l}\text { scale or in different contexts. What may be transformational } \\
\text { within a certain context or level of scale (e.g., an individual or } \\
\text { organization) may not be transformative at a different level }\end{array}$ \\
(e.g., the economy as a whole).
\end{tabular}
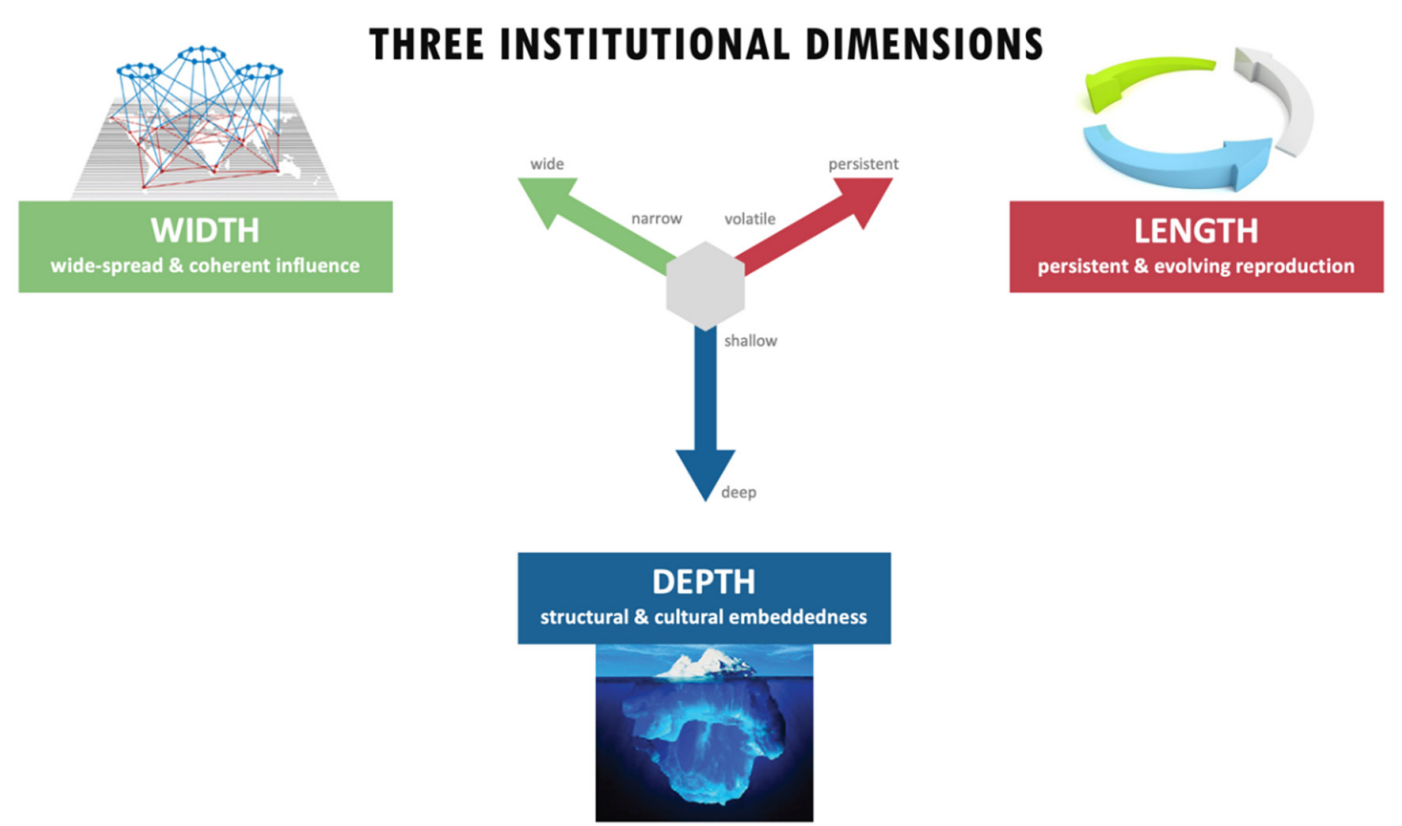

Figure 1. Visual representation of three institutional dimensions, adapted from the original framework [16].

Note that in our initial framework [16], we differentiated between transformative "competences", which taken together constitute "transformative capacity". However, during the application process we chose to use "capacities" instead of "competences", for a number of reasons: Firstly, it became evident that the term "competences" unnecessarily increased the conceptual density of the framework, as it added to the already large number of concepts, which practitioners perceived as barriers for understanding and using the framework. Secondly, the notion of competences is generally more associated with properties of individuals, while capacities are also properties of groups, organizations, or networks as a whole [25-28], which is why capacity is more appropriate to the TSI context of collective agency $[9,23]$. 


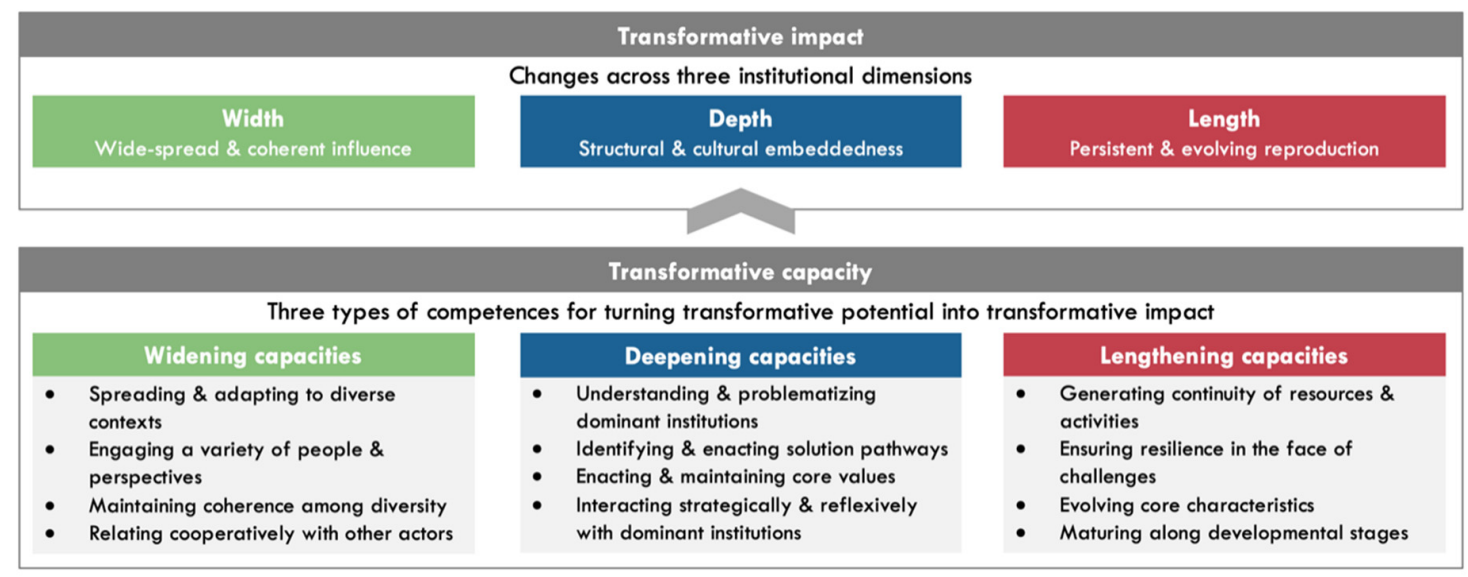

Figure 2. A selection from the original 3D framework [16], focusing on the elements constituting the three dimensions of institutional change and related transformative capacity (the focus of this study). The original framework additionally included learning processes and network leadership as mechanisms to develop transformative capacity and impact.

The transformative capacities offer a capacity-specific lens on mechanisms of scaling or 'trans-local diffusion' [13] of social innovation, as conceptualized in other typologies. These describe different dynamics of how social innovations initiatives develop and interact with dominant institutions: by growing, replicating, partnering, instrumentalizing, and embedding [13,29-31]; deepening, broadening, or scaling-up [32], replicating, scaling-up, or translating [33-35], replicating, scaling, and embedding [36], shielding, nurturing, or empowering [37], scaling out, scaling up, or scaling deep [38]. The contribution of this study in relation to these other typologies is discussed in Section 5.

\section{Methodology}

We employed a multi-method approach [39], using qualitative case studies and embedded action research, to apply and test the 3D framework in a variety of cases of social innovation networks. The following sub-sections explain the case selection criteria, introduce the cases, and describe the methodological approach and specific methods used for data collection and analysis.

\subsection{Case Selection Criteria}

Three criteria guided our selection of cases. Firstly, we sought to balance depth and diversity of cases. We aimed for diversity in geographical context, type of institutions being challenged, and the degree to which the approaches of social innovators were transformative. At the same time, the richness and high degree of complexity of each case called for an in-depth case study approach. Hence, several cases were studied in more detail, others more generally (see Section 3.3).

Secondly, opportunities for active participation and engagement in cases were deemed important. Being able to participate in and co-organize meetings, workshops, and events was required for the in-depth case study work and to apply and test the framework in practice, using an embedded action research approach (see Section 3.3). Therefore, the first author built on pre-existing relationships or personal involvement with most of the case networks to ease access and apply the framework in their network contexts (see Section 3.2). For this reason, the selected cases represent mostly grassroots or community-focused networks, even though social innovation (SI) initiatives also exist in other societal spheres (public, private).

Thirdly, we wished to study multi-level networks, considering that Transformative Social Innovation involves complex, multi-level processes and highly dispersed agency [22]. Multiple social innovation networks aim to contribute to transformative impact at different scales (local, national, regional, global), whereby local initiatives are often embedded in transnational networks [22]. To capture some of this complexity, we focused on two levels of networks: 'meta-networks' and 'member-networks'. 
These are defined below, while recognizing the provisional character of such units of analysis and the high diversity of network configurations [22].

Member-networks are national or transnational networks that mostly support local level participants in SI groups and target policy actors relevant to advancing their specific change ambitions. They usually promote particular SI models or change strategies (e.g., the Global Ecovillage Network promotes the ecovillage model—see Section 3.2.1).

Meta-networks are networks of networks that strengthen exchange, alignment, and collaboration across member-networks and their change strategies. Thereby, they aim to advance transformation at the level of various social innovation (SI) fields [18,40]: a certain sub-system or aspect of society that a variety of actors are involved in or aim to change (e.g., ECOLISE promotes community-led change for sustainability, across its member-networks: Global Ecovillage Network, Transition Network, etc.-see Section 3.2.1). Examples of meta-networks include: RIPESS, the intercontinental network for the promotion of social solidarity economy (www.ripess.org), the Thriving Resilient Communities Collaboratory (TRCC), which promotes community-led initiatives in the United States (www.thrivingresilience.org), or the Wellbeing Economy Alliance (WEAll), which promotes transformation of the economic system globally (www.wellbeingeconomy.org). Their target groups are people engaged in member-networks, as well as organizations, decision-makers, and collaborators operating in or across various sectors, who are relevant to advance changes promoted by various member-networks.

\subsection{Case Description}

We use the notion of "case-clusters" to refer to a collection of member-networks and meta-networks in a specific social innovation (SI) field. We chose cases that met most of the above selection criteria in three SI fields: 1. community-led initiatives for sustainability in urban and rural areas, 2. student-led initiatives for sustainability in higher education institutions, 3. citizen-led peace-building. We briefly introduce the chosen cases per case-cluster below and summarize what makes them (a) socially innovative: the changes in social relationships and related ways of doing, organizing, framing, and knowing (DOFK) they promote; and (b) potentially transformative: how they seek to challenge, alter, or replace dominant institutions. We also briefly describe any pre-existing relationships of the first author to the chosen cases.

\subsubsection{Case-Cluster 1: Community-Led Initiatives (CLIs) for Sustainability in Urban and Rural Areas}

Community-led initiatives focus on engagement and empowerment of community-initiatives to act locally (at neighborhood, village/town, or city scales) to address global sustainability challenges. They promote approaches, such as community-owned and self-managed energy cooperatives, local (social) enterprises, regenerative and cooperative agricultural management that seeks to enhance ecosystem health and social wellbeing, or participatory decision-making via consensus or sociocracy. They aim to cultivate and embody a culture of cooperation, well-being, healing of trauma, personal and community-development, and social equity. Thereby, they seek to challenge and embody alternatives to dominant institutions, including neoliberal economics, global trade and extractive resource production, cultures of individualism, consumerism and materialism, hierarchical decision-making, or neo-colonialism. Table 2 introduces the cases in this cluster.

The first author had some pre-existing relationships with all the cases in this cluster through participating in a few of their events out of personal interest. During the process of this study, he was invited to join ECOLISE's "network health circle" to support their membership strategy development (see Section 3.3). 
Table 2. Cases in the community-led initiatives (CLIs) cluster.

\begin{tabular}{ll}
\hline The Global Ecovillage Network (GEN) (www.ecovillage.org) supports the spread of \\
ecovillages and related lifestyles, practices, and development approaches based on \\
community-empowerment and sustainable living. According to their website, \\
an ecovillage is defined as: "A rural or urban community that is consciously \\
designed through locally owned, participatory processes in all four dimensions of \\
sustainability (social, culture, ecology and economy) to regenerate their social and \\
natural environments". \\
\cline { 2 - 3 } Member-networks \\
Transition Network (www.transitionnetwork.org) supports citizen groups in towns \\
and cities who are "reclaiming the economy, sparking entrepreneurship, \\
reimagining work, reskilling themselves and weaving webs of connection and \\
support". They seek to inspire and empower people to develop more fulfilling and \\
sustainable lifestyles, and to develop resilient local economies. \\
ECOLISE, the European network for community-led initiatives on climate change \\
and sustainability (www.ecolise.eu) provides a common platform across CLI \\
networks and organizations for capacity building, collaboration, policy influence at \\
EU and regional governance levels, and collaborative knowledge development. \\
Most of its members are national to global organizations from the Global Ecovillage \\
Network, Transition Network, and the permaculture movement. Additional \\
members include the ICLEI-Europe network of local authority sustainability \\
initiatives and the Dutch Research Institute for Transitions, among many more. \\
\hline
\end{tabular}

\subsubsection{Case-Cluster 2: Student-Led Initiatives (SLIs) for Sustainability in Higher Education}

Student-led initiatives promote sustainability within higher education institutions (HEIs): universities, universities of applied sciences, business and management schools, or technical and vocational colleges. Mostly, they organize educational and behavioral change activities among the student body, such as sustainability weeks and conferences, campus gardens, self-organized courses, or bicycle repairs. Many also work towards institutional changes, for instance via research-based consulting for HEI staff or municipalities, collaboration with academics for curriculum changes, promoting recycling and waste elimination on campus and meat-reductions in canteens, or sustainability assessment, policy development, and reporting. As such, they challenge and alter HEIs to include sustainability in all curriculum, research, operations, and governance. Beyond HEIs, their transformative ambitions extend to all sectors of society through equipping students to become leaders for sustainability in politics, economics, engineering, law, etc., and fostering more co-creative relationships between academia and society. Table 3 introduces the cases in this cluster.

The first author has been involved as practitioner in the Green Office (GO) Movement since 2014, as workshop facilitator and coordinator of the international network. In this function he organized activities including annual conferences, online exchanges, documentation of good practice, and coordination with partner networks (for details, see: www.greenofficemovement.org/join). He also initiated and supported informal collaborations across members of Students Organizing for Sustainability (SOS) since 2016 and supported the organizational development of SOS since 2019. As such, he also had previous relationships with and attended some events of oikos and other members of SOS.

\subsubsection{Case-Cluster 3: Citizen-Led Peace-Building (CLP)}

The cases in this cluster promote peace and sustainability in contexts of physical and psychological violence (war, racism, patriarchy). Both work on three levels of promoting peace and sustainability: empowering individuals to become leaders in their communities and organizations, supporting community-led approaches for peace-building at neighborhood and city-levels, and convening national cross-sector collaboration for systemic change. No meta-network was found in this case-cluster. Table 4 introduces the cases in this cluster. 
Table 3. Cases in the student-led initiatives (SLIs) cluster.

The Green Office (GO) Movement (www.greenofficemovement.org) promotes the Green Office (GO) Model: a student-led and staff-supported sustainability platform that informs, connects, and supports students and staff to act on sustainability. Unique about this model, compared to most traditional student associations, is (a) the institutional support in the form of an official mandate and budget for salaries and project delivery; and (b) a collaborative relationship between students, university management, and academic staff. Thereby, students are empowered to Member-networks work professionally with these stakeholders on changes in operations, governance, and curricula.

Oikos (www.oikos-international.org) is an international, student-led non-profit organization supporting students to integrate environmental and social perspectives in economics and management education and empowering them to become responsible leaders in business and government. Besides student empowerment, they also collaborate with professors, businesses, and professional experts in finance and management to transform curricula.

Students Organizing for Sustainability (SOS) (www.sos.earth) aims to connect and strengthen student-led networks and organizations working on sustainability in higher education. Members of SOS include international networks (the GO

Meta-networks Movement and oikos); national student unions in the UK, Denmark, and Ireland; national networks in Germany (netzwerk n), Austria, France, and Switzerland; and local initiatives that seek to scale their programs internationally. Activities include cross-network relationship-building and capacity-building, replication of impactful programs, and research on student attitudes on sustainability.

Table 4. Cases in the citizen-led peace-building (CLP) cluster.

Fundación Mi Sangre (www.fundacionmisangre.org) is a citizen-network based in Brazil, promoting a "culture of peace" in a context of wide-spread violence of armed gangs and drug cartels. While a key strategy is empowering youth to become peacemakers in their communities, they also work at a national level to promote policy changes and cross-sector cooperation among public, private, educational, and civil society organizations.

Resonance Network (www.resonance-network.org) is a US-based organization seeking to transform a culture of violence into a culture of peace. They focus, in particular, on gender-based violence, while using gender also as a lens for understanding and challenging systems of violence and oppression more widely and promoting peace in the broader sense of ecological sustainability and social justice.

In contrast to the other case case-clusters, the first author had no previous relationship with or knowledge about these cases. These were identified through the focus groups conducted for this study (see details in Section 3.4), with the purpose of applying and testing the framework in more diverse case contexts.

\subsection{Methodological Approach}

In this subsection we describe the overall methodological approach and explain how ethical issues were addressed. The first author conducted the data collection and analysis, while co-authors contributed to the methodological design and the editing and reviewing of the results and discussion. Generally, the methodological design was guided by considerations in previous research on TSI, regarding units of analysis and methods of inquiry and analysis [41,42].

Overall, a qualitative case study approach [43-45] was employed for all cases. A qualitative approach was chosen as this seemed most appropriate to substantiate and refine the 3D framework elements, in a way that is grounded in a detailed understanding of the complexity and uniqueness of particular case contexts [46]. The primary cases that were investigated in more depth over a period of one or more years were GO Movement, SOS, Global Ecovillage Network (GEN), and ECOLISE; secondary cases that were studied more generally were Transition Network, oikos, Fundación Mi 
Sangre, and Resonance Network. A multi-method approach was employed to triangulate data from a variety of qualitative methods (see Section 3.4) [45,46].

An embedded action research approach [4,47-49] was employed for the following cases: GO Movement, SOS, and ECOLISE. The first author held the positions of an "insider within" [50] by studying his own practice context in the GO Movement and SOS (as described in Section 3.2.2). He was also an active participant in ECOLISE's network health circle, supporting one of their staff members to develop their membership strategy. As part of this active involvement in cases, he organized and facilitated meetings and supported knowledge development, inspired by the 3D framework. This approach enabled easier participant observation and interview opportunities, as well as possibilities to test the framework in practice. It also afforded a better understanding of the goals, culture, and capacity requirements of cases, which would be more difficult to study through interviews from an outsider perspective [48]. In line with normative commitments of previous work in TSI theory development $[9,18]$, and SI research more generally [51,52], we also aimed to develop empowering knowledge. Action research generally aims to contribute value to practice through the research process, instead of merely extracting knowledge, as some social innovation initiatives perceive traditional research [53]. The first author's background in both research and practice, as well as the intention to generate empowering knowledge, served to build rapport with case representatives. His active role in these cases also made testing of the 3D framework more meaningful for the practitioners.

Diagnostic questions were developed (see Appendix B) to structure the data collection for answering our first research question (how the 3D framework can serve to identify and assess transformative impacts and capacities). These were designed by translating each of the framework elements into (1) assessment questions, for identifying impacts achieved and capacities that are well developed, and (2) evaluation questions, for identifying envisioned impacts yet to be achieved and capacities to be further developed. Yet, many practitioners found it difficult to understand what exactly these questions were asking for, given the generic character of the framework elements. Therefore, two to four additional sub-questions were developed for each framework element. However, this further increased the complexity of the framework, as it multiplied the number of issues to consider. Hence, the questions served more as a guide for collecting data about as many elements and relations as possible, while respecting time limitations of participants.

To answer our second research question (how the 3D framework is perceived as recognizable and useful by practitioners), additional questions were included in interviews and focus groups about the recognizability and usefulness of the framework in practice. With "recognizability" we mean: does the framework capture what practitioners see as the most important elements of, and conditions for transformative impact? Does it bring into focus meaningful topics they did not already think of? Does it generally make sense to them? By "usefulness" we mean: how do practitioners see this framework as valuable for supporting their practice? How can they imagine using it? How is it useful to think about these framework elements? Which limitations do they see? Which content adaptations are needed to make it more useful?

Furthermore, the first author tested how the generic framework elements and diagnostic questions could be operationalized into case-specific indicators in three case contexts (GO Movement, GEN, and ECOLISE). This was done by gaining an understanding of their strategic goals, exploring how these goals fit within the framework elements, and proposing specific aspects to consider in those case contexts to assess impacts and capacities. This step helped to identify relevant issues per case, while also testing and enhancing the recognizability and usefulness of the framework in practice. However, the indicators for GEN and ECOLISE were merely of a provisional nature, as these cases needed to clarify their goals internally first. The indicators for the GO Movement are included in Appendix C, while those for GEN and ECOLISE were too provisional to be included here.

Ethical issues were addressed in the following ways. In the cases where the first author was involved as embedded action researcher, his research role was made explicit. Members were asked for consent about the first author's participation in internal events and access to internal documents, 
which were used for the case research for this study. Case respondents were guaranteed anonymity and no confidential data were used or made available, to respect privacy concerns. Case representatives from the SOS and ECOLISE were asked to proof-read a draft version of this article, upon which they confirmed or adjusted the results for accuracy.

\subsection{Methods for Data Collection and Analysis}

In this subsection, we describe the particular methods that were used for data collection and analysis. A combination of at least three different methods of data collection was used in each case-cluster (see Table 5), to apply, test, and refine the 3D framework. See Appendix A for a detailed overview of data sources for each of these methods.

Table 5. Methods applied per case-cluster.

\begin{tabular}{cccc}
\hline Method & Cluster 1 & Cluster 2 & Cluster 3 \\
\hline Participant observation & $X$ & $X$ & \\
Document analysis & $X$ & $X$ & $X$ \\
Focus groups & $X$ & $X$ & $X$ \\
Semi-structured interviews & $X$ & $X$ & $X$ \\
\hline
\end{tabular}

Participant observation [43,54]: A range of conferences, workshops, and meetings were attended (online and in person). Field notes were taken about impacts and capacities that practitioners discussed independently of the framework. These events were also used as opportunities to build relationships to gain access to more information and participation opportunities. They also offered opportunities for conducting focus groups and semi-structured interviews with conference or workshop participants who were highly engaged within the case networks.

Document analysis [43,54]: The following types of documents were collected, coded, and analyzed: research outputs about the selected cases, as well as public and internal reports from the cases, information on their websites, as well as meeting notes, brochures, good practice collections, guides, and toolkits. Thereby, it was possible to draw on available data about the cases to guide and complement data gathering through the other methods.

Focus groups $[43,54]$ were conducted online and in person to apply and test the 3D framework, by drawing on different perspectives of multiple case representatives. Engaging practitioners in dialogue with each other was also a way to make the research process meaningful for practitioners, as they could reflect together with colleagues or peers about their work. Nine focus groups were organized in total: four as part of ECOLISE events, two as part of GO Movement events, and one during an SOS member meeting. Two additional focus groups were organized with leaders from diverse networks as a way to test the framework with more diverse cases and identify additional cases for follow-up interviews. The cases from case-cluster three (Fundación Mi Sangre and Resonance Network) were thereby identified as offering rich examples and valuable feedback.

Semi-structured interviews $[43,54]$ were conducted online and during participant observation events with network coordinators and active members. Two interviews also took place as follow-ups from the focus groups with Fundación Mi Sangre and Resonance Network, as they offered rich examples. The diagnostic questions were used to structure the more in-depth interviews with Fundación Mi Sangre and Resonance Network and were used more loosely (focusing only on a few of them at a time) for shorter interviews with the other cases.

The diagnostic questions were used for all the above data collection methods, though in different ways. The first author used the diagnostic questions for structuring the participant observation fieldnotes and document analysis. A set of hand-written cards containing the diagnostic questions was used during in-person focus groups, to which practitioners could respond with sticky-notes. A shared google document with the diagnostic questions was used for virtual focus groups, which practitioners could fill out simultaneously. The GO Movement specific indicators (Appendix C) were used in a 
self-assessment form that Green Office members could fill out themselves in preparation for a focus group at the GO online summit and for interviews with Green Offices. Finally, the diagnostic questions were used in interviews to ask about specific elements (in shorter interviews) and each element consecutively (in longer interviews).

The abbreviations shown in Table 6 are used in Section 4 to indicate data sources. The source abbreviations are combined with case abbreviations for particular instances of empirical findings. For instance, "PaOb-GEN" indicates a finding from participant observation in the Global Ecovillage Network.

Table 6. Abbreviations per source and per case.

\begin{tabular}{cc}
\hline Source & Source Abbreviation \\
\hline Participant observation & PaOb- \\
Document analysis & DocA- \\
Focus groups & FocG- \\
Semi-structured interviews & Int- \\
\hline Case & Case Abbreviation \\
\hline Global Ecovillage Network & GEN \\
Transition Network & TN \\
ECOLISE & ECO \\
GO Movement & GOM \\
oikos & OI \\
Students Organizing for Sustainability & SOS \\
Fundación Mi Sangre & FMS \\
Resonance Network & RN \\
\hline
\end{tabular}

The empirical data collected through all the above methods were organized and analyzed through the use of codes [55]. Pre-defined codes were defined based on the elements of the original 3D framework [16]: for each of the three types of transformative impact (\#DI for depth impacts, \#WI for width impacts, \#LI for length impacts), for each of transformative capacities (\#DC for deepening capacities, \#WC for widening capacities, \#LC for lengthening capacities). Sub-codes were defined for more specific aspects of each of the framework elements (e.g., \#DC-understanding for the specific deepening capacity of 'understanding and problematizing root causes'). Codes were also defined for recognizability and usefulness (\#Rec, \#Use). Additional codes were defined for interactions among capacities (e.g., \#Int-D-W), as this was found to be an important aspect to include during the process of the study, although we did not address these in much detail. The results about interactions are therefore included in Appendix D, instead of Section 4. Empirical findings of specific types of impacts and capacities that were not yet addressed by the original 3D framework were coded as possible refinements or additions. Hence, while the data analysis was largely based on pre-defined codes, it also involved a minor degree of emergent coding in an inductive manner. The coded data were collected in an overview using a Microsoft Word document, which was structured with headings based on the pre-defined codes, while sub-headings were added for emergent codes. The results were analyzed by comparing the data to the initial framework and identifying ways to concretize and adapt the framework elements based on this data.

\section{Results}

In this section we first describe the findings from applying the 3D framework elements: that is, we present empirical examples that substantiate what the framework elements meant concretely in the case contexts. We also describe how and why some of the original framework elements were refined, or new ones added, in response to the insights gained by applying the framework in practice. Consequently, we present the results about recognizability and usefulness of the 3D framework. Instead of analyzing each case separately from the perspective of the 3D framework, we describe 
overall patterns of transformative impacts and related capacities for each dimension, including diverse case examples.

\subsection{Depth Impacts: Structural and Cultural Embeddedness}

\subsubsection{Recognition by Established Institutions}

Representatives of the UN, national governments, and regional ministries are increasingly showing an interest in the ecovillage development approaches promoted by GEN and other community-led initiatives (PaOb-ECO, DocA-ECO). GEN has also come to be seen as a cooperation partner for universities, corporates, and Non-Governmental Organizations (NGOs) (DocA-GEN). At a local level, some municipalities are very supportive of community-led initiatives and embrace them as innovative approaches. Examples include Steyerberg in Germany, promoting the electric car cooperative initiated by the ecovillage Lebensgarten Steyerberg (PaOb-GEN), or the Sustainable Neighborhoods program initiated by the municipality of Brussels (PaOb-ECO). However, many municipalities are also unsupportive or even block them (DocA-ECO). UNESCO and the German Council for Sustainable Development acknowledged the Green Office as a best-practice model to promote education for sustainable development. In some cases, such recognition involved financial support, in the form of prize money (e.g., the UNESCO-Japan Prize on Education for Sustainable Development (ESD), awarded to the Green Office model) or project funding (e.g., various EU-granted Erasmus+ projects for GEN, Transition Network, and ECOLISE).

\subsubsection{Integration into Established Organizations and Policies}

Unlike most student-led initiatives, established Green Offices are formally integrated as part of the university, receiving an official mandate, office space, salaries, and legitimacy to act for sustainability within their organization [56]. Being structurally embedded and closer to decision-makers is a primary source of influence for Green Offices, setting them apart from other student groups. Many Green Offices have also achieved integration of education for sustainability in higher education curricula and organizational policies encouraging sustainable behaviors (e.g., recycling, vegetarian canteen options, or reducing single-use plastics). Integration can also involve creation of organizational entities, for instance, sustainability coordinators and committees (DocA-GOM), a secretary for peace-building in the Colombian ministry (Int-FMS), state-wide coalitions promoting and resourcing community-based solutions to gender-related violence (Int-RN), and the promotion of ecovillage development as part of the Senegalese government's strategic policy (DocA-GEN). In a few countries (e.g., The Netherlands), ecovillages have succeeded in changing policies for land use and construction regulations to enable ecovillage development, or laws allowing for home-schooling (PaOb-GEN), while some Transition initiatives got municipalities to adopt renewable energy and reusable cup systems and convinced businesses to accept local currencies (DocA-TN). In Frome, UK, citizens even took over the municipality administration by supporting independent candidates standing for elections (DocA-TN).

\subsubsection{Assessment Systems and Incentives}

Some Green Offices conduct sustainability assessment and reporting and offer rewards for sustainability engagement of students: for instance, study credits, certificates (in partnership with academics), or coupons (in partnership with local businesses). Other activities by student-led initiatives, such as the national ranking SustainaBul (www.studentenvoormorgen.nl/en/sustainabul) or the rating of business schools by Positive Impact Rating (www.positiveimpactrating.org), assess higher education institutions and thereby incentivize them to improve their sustainability performance. Fundación Mi Sangre also works on changing assessment criteria by which students and teachers are evaluated, so as to create incentives to educate for whole-person leadership (Int-FMS). They also seek to create mechanisms whereby employers select and evaluate young people based on their sustainability competences (Int-FMS). 


\subsubsection{Changes in Values, Norms, and Behaviors}

Green Offices have inspired students and staff to adopt sustainability values and related behaviors, such as vegetarian and vegan diets, energy saving, waste reduction, sharing resources, and expecting or inviting those behaviors from each other (social norms) (FocG-GOM, Int-GOM). Thousands of people who visit ecovillages to attend their courses change their lifestyles and initiate sustainability projects or community initiatives inspired by this experience (DocA-GEN). Some municipalities have adopted more participatory deliberation and decision-making processes as a result of cooperating with Transition initiatives and being inspired by their facilitation methods (DocA-TN).

\subsubsection{Changes in Ways of Thinking (Mindsets, Beliefs, Discourses)}

Some municipalities have changed their perception of community-based organizations as professional partners (DocA-TN). In some instances, university staff changed their view of students as competent and accountable change-makers (DocA-GOM). Prejudices towards low-income communities as dangerous slums changed as citizen-led graffiti tours in shanty towns shifted people's image of these places (Int-FMS). GEN and Resonance Network contributed to wider acknowledgement of the role of worldviews as foundational for sustainability and peace-building ( $\mathrm{PaOb}-\mathrm{GEN}$, Int-RN). Many educational organizations have realized the importance of supporting inner change for conscious leadership, while citizens see young people more as leaders and positive role-models, not just "typical leaders who are male and in their 50s" (Int-FMS). Widely influential ways of thinking can be barriers for SI models to become more widely adopted. For instance, ecovillages being seen as "hippie communes" (PaOb-GEN), or university staff not considering students as competent leaders (Int-GOM).

\subsubsection{Changes in Power Relationships}

Some university staff members remarked how the Green Office model challenges the traditionally more top-down relationship between staff or academics and students (PaOb-GOM), turning it into a more collaborative relationship on equal footing. Similarly, an example from Transition Network is a change in relationship through "approaching the council with an invitation, an offer, where the community is in the lead, rather than criticizing them or requesting to receive something" (DocA-TN).

This element was added to the 3D framework, as we recognized that the issue of power was not explicitly addressed in the original framework, while being a fundamental aspect of Transformative Social Innovation $[9,57,58]$.

\subsection{Deepening Capacities}

\subsubsection{Understanding and Problematizing Root Causes}

Most cases focus on raising awareness, especially among people who are not yet aware, of the urgency of sustainability challenges and how different systems (food, fashion, energy, transport, finance, etc.) contribute to problems of unsustainability and injustice. In the community-led cluster, the books, reports, or webinars of inspirational thought leaders or network leaders were seen as influential in building an understanding of systemic root-causes (Int-ECO, PaOb-GEN, PaOb-ECO). Examples include the writings and talks of Daniel Christian Wahl [59] or Charles Eisenstein [60] on the need for moving from degenerative socio-economic systems based on scarcity, separation, and extraction to abundance, wholeness, and regeneration. While less pronounced in the student-led initiatives cluster, in all cases it was found to be important to go beyond surface issues and to question established systems at a deeper level. Issues that were recurrently problematized were the capitalistic economic system geared to endless growth, individualistic consumer culture, patriarchy and neo-colonialism, a mechanistic worldview, and mindsets of separation and domination. One ECOLISE staff member suggested (Int-ECO) that many community-led initiatives could develop more systemic intervention approaches that identify and organize activities around systemic leverage points that 
are based on rigorous scientific systems analysis. He also mentioned that researchers could make a valuable contribution here.

This element was refined from "understanding and problematizing dominant institutions" in the original framework to be more concrete about the importance of identifying deeper root causes.

\subsubsection{Identifying and Practicing Effective Solutions}

Most of the efforts of the studied cases are focused on developing concrete events, projects, campaigns, and programs to promote the changes they wish to see (such as educational activities, festivals, conferences, consulting services). A shared mentality among the cases was to have a constructive and pragmatic approach by offering concrete solutions or alternatives to current problems, instead of (or in addition to) criticizing or demanding powerful decision-makers to act. In all cases, three levels of change activities could be distinguished: 1. the individual level (awareness raising, leadership development), 2. the collective level (community-building, community engagement, and networking) and 3. the systemic level (influencing policy and convening high-level leaders and decision-makers across sectors). Some cases found it important to develop rigorous theories of change (FocG-FMS), though a more common emphasis was on developing compelling visions or narratives of desired futures, as well as embodying or role-modeling the change they wish to see in individual behaviors and their organizational culture and structure (PaOb-ECO, PaOb-GEN, FocG-GOM). Most case networks developed elaborate solution inventories, success stories, and good practice guides to inspire and support effective action in different domains. Examples include GEN's Solution Library (www.ecovillage.org/solutions), Transition Network's project examples (www. transitionnetwork.org/do-transition/transition-in-action), or the good practice resources on the GO Movement website (www.greenofficemovement.org/sustainability-resources).

This element was refined from "identifying and enacting solution pathways" in the original framework, as "identifying and practicing effective solutions" was considered to be more concrete and understandable in practice.

\subsubsection{Clarifying and Enacting Core Principles and Values}

For social innovations that are based on specific models that can be applied in different contexts (an ecovillage, a Transition initiative, or a Green Office) it was found to be important to distil the essence of those models into a set of core principles that encapsulate their transformative qualities. Examples are GEN's Map of Regeneration (www.ecovillage.org/projects/dimensions-of-sustainability), Transition Network's healthcheck (www.transitionnetwork.org/resources/health-check), and GO Movement's Team Health Check (www.bit.ly/GO-Health-Check). These principles describe the "essential ingredients" (DocA-TN) that are deemed to make these SI models effective in generating the desired changes: "It's the most important secret sauce that we have, more than the methodology itself" (Int-FMS). Often these were developed over multiple years by synthesizing the learnings from what worked across diverse local adaptations (DocA-GEN, PaOb-GOM). The articulation of shared values (within and across social innovation networks) was of recurring importance, especially for those networks that were less focused on a specific model (PaOb-ECO, Int-FMS). Examples in the ECOLISE context were: care, cooperation, co-creation, social justice, and ecological integrity (DocA-ECO). ECOLISE members emphasized that it is especially important to operationalize those values in action (Int-ECO, PaOb-ECO). Similarly, oikos makes values a core element of their organizational culture and also supports students to clarify and enact their values on a personal level, so as to become responsible leaders in their careers (PaOb-OI). Values were generally seen to act as a core mechanism for embodying the change that social innovators wish to see, and to avoid co-optation by institutions they wish to change (Int-ECO, PaOb-ECO).

This element was refined from "clarifying, enacting, and maintaining core values" in the original framework, as we found that the aspect of "maintaining" belongs instead to lengthening capacities ("generating continuity of activities and resources") and the following deepening capacity. 


\subsubsection{Cooperating Strategically and Reflexively across Sectors}

All cases emphasized the need to cooperate with high-level decision-makers in government, business, or academia to further their transformative ambitions or address complex challenges in integrated ways. They lobby for formal recognition and supportive financial or legal frameworks, apply for funding or formal mandates, or invite partnerships for collaborative action. Having good relationships with people in those institutions (e.g., Members of the European Parliament, faculty deans in universities, council members in municipalities) who support their cause was seen as critical.

However, "cross-sector gaps" (Int-ECO) were seen as challenging, for various reasons. Oftentimes, misunderstanding, skepticism, or prejudice (e.g., "anti-private sentiments", businesses as "the enemy") were seen as barriers for community-led and student-led initiatives to cooperate with public and private actors. Hence, "the art of convening" (FocG-ECO) to create trust, understanding, and willingness to cooperate across sectors was deemed important. Transition Network initiated the Municipalities in Transition project (www.municipalitiesintransition.org) to strengthen cooperation among municipalities and Transition initiatives. ECOLISE cooperates with the European Rural Parliament (PaOb-ECO), while some ecovillages cooperate with farmers, citizen groups, and municipalities for spreading their solutions in traditional villages (see the "Living in Sustainable Villages" project by GEN Germany: www.gen-deutschland.de/leben-in-zukunftsfaehigen-doerfern). Green Offices cooperate with other student groups, staff initiatives, companies, and municipalities for joint projects on awareness-raising, behavior change, and institutional change projects (FocG-GOM, DocA-GOM).

Maintaining autonomy and not losing their radical edge was seen as a challenge when cooperating or receiving institutional support. Cooperation may require making compromises in favor of the interests or requirements of funders or decision-makers. For instance, a few Green Offices have lost some of their student-led qualities as they had to give way to more powerful staff-led initiatives (Int-GOM). Similarly, some town councils have appropriated the actions of Transition initiatives [61]. Hence, all cases found it important to find ways of avoiding or dealing with such situations and reflect critically about how core principles may be lost, or dominant institutions reproduced in undesirable ways. This tension between cooperation and autonomy was often found to be difficult to navigate.

This element was refined from "interacting strategically and reflexively with dominant institutions" in the original framework, as emphasizing cross-sector cooperation was seen as more concrete. It also made this element more distinct from the widening capacity "cross-movement collaboration".

\subsubsection{Challenging Dominant Power-Structures}

The nature of power structures is a topic that was discussed in many of the networks studied. This topic was frequently seen as deserving more explicit attention and practitioners found that more skillful ways of dealing with issues of power need to be learnt (PaOb-ECO). Various "systems of oppression" were mentioned (PaOb-ECO, PaOb-SOS, FocG-RN), such as white supremacy, racism, neo-colonialism, patriarchy, or classism [62-64]. Many practitioners perceived it as foundational to create conditions for inclusivity, equity, and diversity, since transformative ambitions will have little impact if socially innovative solutions only remain accessible to the privileged (i.e., less width), or if they unwittingly perpetuate deeper power structures as part of their activities and organizational structures (i.e., less depth). For the studied cases, this involved not only challenging external structures (e.g., campaigning against unjust policies) (Int-RN), but also internalized power structures; for example, by "unlearning" sub-conscious attitudes, such as a "capitalist mindset" (FocG-ECO), and habits, such as giving less credit to female or non-white voices (PaOb-GOM, Int-RN). Some cases developed specific guides, practices, or workshops to strengthen this capacity (DocA-GEN, DocA-TN, PaOb-SOS).

This element was added to the 3D framework, as we recognized that the issue of power was not explicitly addressed in the original framework, while being a fundamental aspect of Transformative Social Innovation $[9,57,58]$. 


\subsubsection{Reconciliation and Healing of Trauma}

Addressing issues of reconciliation and restorative justice in relation to historical oppression, violence, and exploitation (resulting from neo-colonialism, racism, patriarchy, etc.) was seen as deeply important in the contexts of community-led initiatives and citizen-led peace building. Recognizing and addressing such deep-seated wounds not just in individuals but among oppressed communities (indigenous, non-white, etc.) plays a central role in the peace-building work of Fundación Mi Sangre and Resonance Network (Int-RN, Int-FMS). GEN co-organized a Collective Trauma Online Summit (www.collectivetraumasummit.com), which emphasized the fundamental role of trauma in re-producing collective systems of violence and unsustainability, affecting humanity as a whole. In the Transition network, people involved in 'Inner Transition' [65] groups "realized how much of the violence we inflict on nature and others comes out of the violence we inflict on ourselves on the inside. Working on regeneration is healing this inner violence" (FocG-ECO). Inner Transition groups support people to undergo profound psychological and cultural change to respond to global challenges, while avoiding burnout and nurturing personal and planetary well-being.

This element was newly added to the original framework, as it surfaced in two of the three case-clusters as one of the deepest dimensions of transformation, while being often overlooked (indeed, also in our original framework). We also deemed it important to include this element, considering projections that intensifying climate-change related crises (which tend to affect the marginalized more than the privileged) will surface historical wounds of injustices and oppression [66-68] and that addressing these is core to the psycho-cultural aspect of deep societal transformation $[66,69]$.

\subsection{Width Impacts: Wide-Spread and Coherent Influence}

\subsubsection{Geographical and Cultural Spread}

The studied cases have spread their social innovation models and approaches in countries around the world, to varying degrees. For instance, around 10,000 ecovillages and similar intentional communities exist globally in both traditional villages and newly set up communities (DocA-GEN). Around 1200 Transition initiatives exist in 50 countries (DocA-TN). A total of 47 Green Offices exist in nine countries and more are launching every year; though, with a few exceptions most Green Offices are located in northern and western Europe (DocA-GOM). So far, 49 local oikos chapters exist in 23 countries across the globe (DocA-OI). Yet, while there may be many of such models in a given country, the reach and engagement are often still limited to groups who are already aware, interested, or able to engage in the solutions these initiatives promote. While individual Green Offices reach hundreds if not thousands of students and staff with their activities, these are often from sustainability-oriented study programs or people interested in ecological sustainability. Only a few reach beyond more privileged socio-economic populations to those generally most vulnerable to threats of climate change (PaOb-GOM). Similarly, many northern ecovillages are mainly known by sustainability-minded people and often accessible only to those with sufficient financial resources (PaOb-GEN).

\subsubsection{Adaptation to Diverse Contexts}

As the studied networks spread their social innovations, they have also been adapted to suit different kinds of cultural, geographic, socio-economic, and organizational contexts. Ecovillages and some of the solutions they promote have been adapted to traditional villages in southern contexts, some also in cities (eco-neighborhoods, urban ecovillages) (DocA-GEN). Some ecovillage solutions are being applied in schools, refugee camps, and areas afflicted by natural catastrophe. The Transition model itself can be seen as an urban outgrowth of ecovillage and permaculture movements (DocA-ECO). The Transition approach has been adapted in towns, villages, cities, universities, and schools (DocA-TN). Besides traditional universities, Green Offices are also increasingly being adapted at universities of applied sciences, some professional colleges, and two exist at a school and a municipality. 


\subsubsection{Coherence of Core Principles across Diverse Adaptations}

The social innovation models studied are adapted to local contexts in highly diverse ways, unlike more traditional franchise models. A recurring pattern was observed that local groups differ according to how strongly they are aligned with the core principles that make these models (potentially) transformative. For example, some ecovillages have well-developed activities in all four dimensions of sustainability (PaOb-GEN), and some Green Offices demonstrate strong institutional influence and community engagement ( $\mathrm{PaOb}-\mathrm{GOM})$. Others only embody these elements to a lesser degree, as they have other needs, priorities, or ambitions, or are more constrained by context conditions. However, as many of the networks were in the process of gathering data to assess coherence at the time of this study, little concrete evidence could be found for this element.

\subsection{Widening Capacities}

\subsubsection{Spreading and Adapting SI Approaches to Diverse Contexts}

GEN and GO Movement have various courses, trainings, learning materials, consulting services, and ambassadors for spreading their ecovillage and Green Office models. GEN runs a variety of programs for spreading ecovillage approaches in traditional villages, schools, refugee camps, and areas of natural catastrophe and offers consulting for development ministries to adopt ecovillage development, especially in southern countries (DocA-GEN). GO Movement team members offer consulting, workshops, and online courses and spread the Green Office model via conferences and active outreach and support to students and staff in different countries and organizations (PaOb-GOM). Again, the ability to distil core principles that encapsulate the essence of these models was a catalyst for spreading them more widely and adapting them (PaOb-GEN). At the local level, individual ecovillages and Green Offices also organize activities, such as courses, conferences, and festivals, to inform, engage, and support people to adopt sustainable behaviors and values. A common emphasis for student-led and community-led initiatives lies on showcasing working examples of solutions people can engage with and the importance of storytelling to make these solutions and their vision for change attractive and convincing. Another common concern was replicability of their models in contexts with less wealthy or supportive institutional contexts than northern and western Europe (PaOb-SOS, PaOb-ECO).

\subsubsection{Engaging a Variety of People and Perspectives}

For most cases studied it was highly important to widen the radius of people they are able to attract and engage as participants, members, or ambassadors. Some have created programs or organizational conditions to make their models and activities accessible to and inclusive of diverse people with regard to income-levels, socio-economic status, identities (national, racial, religious, sexual, etc.), abilities, interests, etc. For example, most Green Offices offer volunteer engagement opportunities to reach well beyond their core team and some partner with study associations to engage student populations of various disciplines and interest groups (FocG-GOM). GEN have created programs to adapt ecovillage solutions to refugee camps. Equity, diversity, and inclusion are recurrent topics across community-led initiatives (though to varying degrees), especially reaching beyond privileged white middle-class populations (PaOb-ECO). However, this can also be the other way around when social innovators are working specifically with under-privileged people: a representative of Fundación Mi Sangre stated that they could widen their engagement by involving more upper-class people and training more highly-educated students as leaders, as their focus has been low-income communities so far (Int-FMS). A few focus group participants observed that social innovators can tend to operate within the comfort zone of like-minded, like-abled, like-educated, etc.; however, "transformation happens at the edges of comfort zones" (FocG-RN). A recurrent challenge mentioned was using language that resonates more widely with people who are not yet familiar with the topics promoted by SI actors, while avoiding appropriation or dilution of core values and principles ( $\mathrm{PaOb}-\mathrm{ECO})$. 


\subsubsection{Cross-Movement Collaboration}

Collaboration with initiatives or networks with similar visions was seen as important for all cases for various reasons: to exchange strategies, spread successful activities at wider geographic scales, and build synergies among complementary approaches that different initiatives or networks offer. For example, the GO Movement adopted the Green Impact program (a staff-focused behavior change program) from the National Union of Students in the UK and delivered it in the Netherlands and Belgium while integrating it with the Green Office model (PaOb-GOM). For this to work, the importance of building trust-based relationships and bridges across a diversity of movements was repeatedly emphasized (PaOb-SOS, PaOb-ECO). The meta-networks ECOLISE and SOS play a key facilitating role in strengthening trust-building, communication channels, exchange of experience and projects, and devising joint activities across movements (e.g., ECOLISE's European Day of Sustainable Communities: www.sustainable-communities.net). Some emphasized the importance of going beyond the "usual suspects" and collaborating with diverse, or "provocative" kinds of movements (e.g., hackers, social justice activists, indigenous groups) to expand perspectives and confront one's assumptions (PaOb-ECO, FocG-FMS). However, exclusion of partners can also be part of the bridging process, when core values, agreements, or the image of a movement are threatened [70].

This element was refined from "cooperating with other actors" in the original framework, to more concretely differentiate "cross-movement collaboration" as a widening capacity and "cooperating strategically and reflexively across sectors" as a deepening capacity.

\subsubsection{Building Coherence across Diversity}

Defining what an ecovillage is was an ongoing discussion with many divergent opinions in the ecovillage movement. GEN helped to build coherence by co-creating a definition, a set of core principles (the 'Map of Regeneration'), and a glossary of terms that are agreeable for many. Their principles have also been translated into an Impact Assessment tool (www.ecovillage.org/resources/impact-assessment) and a card deck that can then be used by ecovillages, trainers, and consultants to evaluate and design ecovillages in a way that aligns with these core principles. Similar approaches were seen with Transition Network's healthcheck, which describes "essential ingredients" (DocA-TN) of Transition and offers trainings and learning materials for each. In the GO Movement, six core principles were developed, plus three different archetypes of how these principles can be applied in different university contexts. GO Movement's Team Health Check tool (inspired by Transition Network) and the GO Impact Evaluation tool (based on the 3D framework, see Appendix C) support coherence building, as well as workshops, online courses, and peer learning events. Network coordinators of GEN, Transition Network, and the GO Movement were concerned that the overall impact, image, or legitimacy of their respective networks can be weakened if only a small percentage of local groups apply these core principles, or if any group can use their label without practicing these principles.

\subsection{Length Impacts: Persistent and Evolving Reproduction}

\subsubsection{Long-Term Persistence of SI Approaches}

So far, $95 \%$ of Green Offices have persisted beyond their initial funding period (typically one to two years), while $5 \%$ have been closed down after a few years of activity and a few more have seen their budgets being cut. However, the vast majority have been able to maintain or increase their size and institutional support over time, as well as the size and quality of projects and relationships within and outside of the university (PaOb-GOM). Many ecovillages have existed for over 30 years, demonstrating the viability and durability of ecovillage approaches, if strong foundations are in place. On the other hand, $90 \%$ of newly starting ecovillage initiatives disband within their first year due to internal difficulties (PaOb-GEN). 


\subsubsection{Continuous Individual Engagement}

Green Office alumni who participated in the online summit stated that their experience of working at the Green Office significantly empowered them to continue acting as sustainability change-agents after their studies (FocG-GOM). Similarly, many oikos alumni became influential leaders for sustainability in their careers in business, finance, and management (PaOb-SOS). This was seen as related to the deep learning experiences from their involvement in the Green Office or oikos movements, where they developed sustainability values and change-maker attitudes and competences. In the ecovillage context, the continuous leadership of youth growing up in ecovillages like Tamera can be seen as a persistent impact, considering that some ecovillages lose momentum as the founding generation grows older (DocA-GEN).

\subsubsection{Increases in Width and Depth over Time}

Generally, during the framework application it became evident that the framework element "evolving reproduction" was difficult to distinguish from the lengthening capacities "evolving goals and strategies" and "maturing along developmental stages" (see Section 4.6), or from changes in depth and width impacts (Sections 4.1 and 4.3). We therefore found that evolutionary development impacts can be understood as increases over time in the width and depth dimensions of impact, rather than being a separate category of transformative impact. For instance, in a few universities the activities of Green Offices have led to more staff-led sustainability approaches being initiated, in addition to the student-led Green Offices (increasing levels of structural embedding) (Int-GOM). Also, these students and staff-led activities have become more integrated in some universities (increases in coherence) (Int-GOM). However, in at least one instance the stronger focus on staff-led approaches curtailed the influence and autonomy of the Green Office (decrease in embedding and persistence) (Int-GOM). Also, the fact that the Green Office model was applied to the municipality in Amsterdam (DocA-GOM) (increase in spread and structural embedding) could be seen as an evolutionary development.

\subsection{Lengthening Capacities}

\subsubsection{Generating Continuity of Resources and Activities}

Finding sources of continuous funding was often seen as foundational to ensure persistence of social innovations. Most Green Offices receive annual budgets for salaries and projects from their universities thanks to their lobbying efforts (PaOb-GOM), while oikos chapters mostly apply for project funding from private donors and foundations ( $\mathrm{PaOb}-\mathrm{OI})$. The studied networks commonly explore mixed income models that combine different funding sources, including foundation grants, prize money, public funding for educational programs or knowledge development projects, membership fees, and selling services, such as workshops or courses (PaOb-SOS, PaOb-ECO). However, most of the studied cases only have few, if any, paid staff positions for network coordinators and local groups and rely heavily on volunteers and unpaid extra hours from staff. So, besides finding viable financing models, they also need to secure ongoing motivation and engagement among volunteers, as well as transfer of knowledge, stakeholder relationships, and projects across people joining and leaving these initiatives, sometimes in relatively short cycles. Most cases highlighted the need for creating livelihoods and professional work opportunities, to go beyond volunteerism. For student-led initiatives, continuous engagement of alumni after graduating was another continuity challenge, given their ambition that graduates become sustainability change-makers in their careers (PaOb-SOS). In ecovillages, continuity also applies to cross-generational transfer of the knowledge, attitudes, etc., for youth who grow up in ecovillages to continue living in and co-developing those places (PaOb-GEN). For southern contexts, ecovillage approaches also focus on maintaining existing traditions and community relations to avoid their replacement by western development approaches (PaOb-GEN).

This element was adapted from "generating continuity of resources, activities, and essential elements" in the original framework, as the notion of "essential elements" was found to be too vague 
by practitioners. Aspects such as values, knowledge, motivation, principles are considered part of resources and activities.

\subsubsection{Ensuring Resilience in the Face of Challenges}

Considering that $90 \%$ of ecovillage initiatives fail within their first year due to internal group conflicts, GEN developed a good practice guide (clips.gen-europe.org) and related trainings to help initiatives overcome such difficulties (PaOb-GEN). For instance, key capacities addressed by the guide are having a clear shared vision, written agreements, and processes for decision-making and dealing with conflict. Resources on comparable topics could be found on the websites and support offers of Transition Network and the GO Movement. Ensuring continuous support from municipalities or university decision-makers is another key lengthening capacity for Transition initiatives and Green Offices, as the continuity of their resources and activities can be threatened by changes in elected public officials or university presidency (DocA-TN, PaOb-GOM). Building supportive relationships with multiple staff or technicians who stay in their positions for longer time than elected officials was seen as a key condition to overcome this challenge (DocA-TN, PaOb-GOM). Responding to external challenges, such as funding cuts, natural disasters, or the recent COVID-19 pandemic also requires social innovators to respond in creative ways to avoid a discontinuity of their efforts (PaOb-GOM, DocA-GEN).

\subsubsection{Evolving Goals and Strategies}

This involves further developing core principles, theories of change, narratives, and related strategic interventions over time. For example, Transition Network changed their narrative from "responding to peak oil" and threats of economic and climatic instability, to "rebuilding and re-imagining our communities", as they realized that such positive framings were more conducive to getting people engaged (DocA-TN). Another example is that most cases are moving more of their activities (meetings, conferences, workshops, etc.) online to bridge geographic and cultural gaps and increase accessibility ( $\mathrm{PaOb}-\mathrm{SOS}, \mathrm{PaOb}-\mathrm{ECO}$ ). Many cases also highlighted the need to be able to change what is not effective and navigate complex change processes with flexibility and responsiveness to learn and adapt over time (PaOb-ECO, PaOb-GOM). For instance, initial GO Movement leaders shifted from a for-profit consultancy approach to an open-source movement approach, after realizing that it was difficult to sell consulting services in this sector and that they could have much wider impact via freely spreading the GO model (PaOb-GOM). Yet, some cases expressed difficulties with being confined by requirements of funders to deliver programs according to fixed goals and plans. However, founders of social innovation initiatives can also block further evolution if they are overly attached to their vision or seek ownership or control in place of inviting co-creation (PaOb-SOS).

Many also stated the importance of accelerating their efforts to "go further, faster", in response to the rising urgency of societal problems (PaOb-SOS). An ECOLISE staff member emphasized the importance of responding to societal trends of rising awareness and perceived urgency of climate change, "to step up and showcase the decades of work that has been done to offer viable alternatives $[\ldots]$ and step in from the margins to the center and show ready-to-go initiatives" (PaOb-ECO). Yet, ECOLISE and SOS members also cautioned that such acceleration needs to be balanced with taking the time to slow down, reflect deeply, and support initiatives to mature, instead of "growing too fast" and risking dilution of core principles (FocG-ECO, PaOb-SOS).

This element was adapted from "evolving core characteristics" in the original framework, as "goals and strategies" made this more concrete.

\subsubsection{Re-organizing and Decentralizing Governance Structures}

As the studied cases grew and matured over time, many needed to re-organize their organizational structures and processes. Members of ECOLISE and Transition Network emphasized the need to go beyond traditional hierarchical organizational structures found in most NGOs, companies, 
and governments and adopt more innovative, agile, and participatory structures ( $\mathrm{PaOb}-\mathrm{ECO})$. Stated reasons included the need to be 1 . more responsive through faster and better decision-making that is aligned with needs of members and changing context conditions, and 2. more inclusive through engaging a larger number and diversity of people. Sociocracy and other forms of decentral self-organization within and across networks were found in Transition Network, GEN, and ECOLISE.

The formation of multi-layered networks was common across cases as one way of decentral organizing. For instance, besides the global network, GEN formed national (Germany, Netherlands, etc.) and regional (Europe, Asia, etc.) constituent networks (PaOb-GEN). Similarly, oikos initiated regional and thematic groups (PaOb-OI) for oikos chapters to connect according to geographic proximity or shared interests. Decentralization can also apply at the local level of individual initiatives. For instance, Green Offices initiated volunteer teams or ambassadors at different faculties or campus locations who work in coordination with a central Green Office (Int-GOM).

Decentralization was seen as an important lengthening capacity for multiple reasons. It can strengthen resilience, as local groups and the network at large are less dependent on the continuity or effectiveness of central individuals or organizations (Int-GOM, PaOb-GOM, PaOb-GOM). It can also help with accessing resources at different levels (e.g., local, national, and transnational, e.g., EU or UN funding streams) (PaOb-ECO).

This element was added, as a more specific and distinct framework element that was previously considered part of "evolving core characteristics" and "maturing along developmental stages" in the original framework.

\subsubsection{Maturing along Developmental Stages}

Being able to build on and learn from past efforts was seen as key for social innovators to develop more sophisticated solutions over time. For instance, in ecovillages intergenerational knowledge transfer is a key issue: "movement building requires accumulative knowledge so that each younger generation doesn't start at square one again" (DocA-GEN). Most networks studied give bountiful attention to capturing the learnings from diverse local groups and making those visible and accessible for others to build on (through courses, trainings, conferences, guides, wikis, etc.). Green Offices and Transition initiatives tend to develop in similar phases-initiating, starting, expanding, and re-structuring-and specific support is offered for each of those developmental stages (DocA-TN, DocA-GOM).

The studied networks also went through different stages of development. An ECOLISE staff member suggested that the development of national, international, and transnational network structures (such as ECOLISE) is itself a sign of maturation of community-led initiatives (Int-ECO). This was seen as maturation, as the member networks like GEN and Transition Network first needed to mature internally before they could organize in more complex ways and collaborate across movements (Int-ECO).

Finally, maturing also applies at the individual level. All networks studied focus on supporting individuals to develop to more sophisticated levels of competence, engagement, and leadership: for example, from attending an event, to signing up to a course, to joining as a member and taking on more responsibilities in the initiative or promoting the desired changes in wider society. A recurring approach was to offer diverse pathways for individuals to develop their competences and levels of engagement over time (PaOb-GEN, DocA-TN, PaOb-ECO, PaOb-SOS).

\subsection{Recognizability}

Overall, the framework appeared very much aligned with what practitioners deem important or necessary for transformative change to occur. In many of the discussions and workshops attended, conversations naturally focused on many of the elements in the framework without having introduced the framework to them beforehand. Many practitioners were very enthusiastic about the framework after explaining it to them during participant observation events, focus groups, and interviews. For example, during a focus group at an ECOLISE workshop, one participant responded that 
"the elements capture most of the critical components of transformative capacity" (FocG-ECO). Similarly, a network leader from GEN remarked: "this is fantastic, it speaks so much to the questions we are asking in GEN" (FocG-ECO). Another participant found it an "elegantly simple representation of complexity, without being simplistic. This is difficult and rare" (FocG-ECO). For all cases the intention of the framework resonated with their understanding that for realizing their transformative ambitions, it is critical: 1 . to identify the kinds of capacities needed for social innovation actors to be effective, and 2. to learn how to create contexts for developing those capacities. For this reason, a few respondents offered significant support in co-organizing and facilitating focus groups to test the framework and provide feedback about the framework elements.

Critical points were raised on three issues: 1. the use of abstract concepts, 2. unclear categories, and 3. unclear language. Firstly, some of the framework elements were seen as quite abstract and as such difficult to understand or relate to, without concrete examples or case-specific questions. In response to this, sub-questions for each of the framework elements were developed (Appendix B), as well case-specific indicators for some of the cases (see Section 3.3 and Appendix C). Secondly, when applying the 3D framework, some were unsure which of the three dimensions a certain impact or capacity belonged to: e.g., "is maintaining core values a lengthening and/or a deepening capacity?" (Int-RN), or "when many organizations changed their culture is that width [wide spread] and/or a depth impact [cultural embedding]?" (Int-FMS). This speaks to the high degree of interaction among the three dimensions, which is further discussed in Section 5 (also see Appendix D). Thirdly, some found certain notions confusing or unclear, such as "social innovation (SI) elements" and "dominant institutions": "are dominant institutions political parties, or organizations like universities, schools or companies? Or things like patriarchy, white supremacy, etc. that often underly those institutions?" (FocG-RN). These terms were therefore clarified or avoided in the refined elements of the 3D framework.

About the notion of "transformative impact", a few practitioners expressed the difficulty of knowing if or how their activities have caused or contributed to those impacts and how to differentiate this from general changes they have observed in society that may have come about due to a variety of factors. Indeed, impacts are co-produced and causality notoriously difficult to ascertain. Therefore, we emphasized the focus on contributions to transformative impact, recognizing the role of other actors and factors in co-producing impacts (see Section 2). One focus group participant stated that it "felt like a revelation to see the impact of my network versus impacts of other networks [ ... ] that transformative impact is not something one network can achieve alone. It was valuable to be challenged to think beyond our own impact as an organization" (FocG-FMS).

A recurring point of confusion was that many case respondents tended to focus on the embeddedness, influence, or persistence of a specific project or campaign instead of the social innovation (SI) elements. To clarify: in the 3D framework the important question regarding transformative impact is how deeply embedded, wide-spread, and persistent those SI elements are. For instance, this would mean that community-based regenerative ways of working and living have become a norm in economic development approaches, or student leadership for sustainability has become a norm in higher education curricula and governance. A large degree of length would entail a persistence of those elements independent of the continuation of organizations, such as GEN or Transition Network, who promote them. This could be the result of those elements being deeply embedded and widely spread in many organizations and societies.

One ECOLISE member mentioned that he struggled to understand how the 3D perspective helps to tackle the inertia of dominant institutions, recognizing that all the efforts in community-led initiatives have yet achieved rather little to fundamentally change these (FocG-ECO). Possible responses could be that it can be used to identify ways of challenging the spread, persistence, and embeddedness of those institutions (awareness-raising, unlearning, offering alternatives), or using the 3D perspective to develop the capacities that can enable deep and wide-spread scaling of alternatives offered by social innovations, once established institutions become increasingly unstable or eventually collapse. 


\subsection{Usefulness}

The most common response of practitioners was that they found the 3D framework very useful as a lens for understanding and reflecting about transformative impact and what is needed to make it happen: as a way to be more aware of and intentional about one's impacts and strategies. The representative of Fundación Mi Sangre saw it as a "very useful framework to describe the impact at different levels, much more than what we use to do that today". She added that "it's the first clear, schematic, and simple framework to analyze and to describe everything we've done", in contrast to other frameworks for system change or scale that only focus on some of these elements. Recognizing that "simple" could be seen as something negative (i.e., simplistic), she clarified that she sees it as "very valuable precisely because of the simplicity" (Int-FMS). A few respondents also emphasized the value of collectively reflecting and exchanging perspectives with their colleagues about the framework elements (FocG-FMS, Int-ECO).

For initiatives that are still in the initial stages of development, the framework was also seen as useful to intentionally consider all the elements when designing their interventions (Int-FMS). One network leadership expert suggested that for many networks she knows of, thinking about transformative impacts and capacity is "really new stuff" and that it would be very relevant for them to consider this framework to be more intentional and strategic specifically about transformative change and to realize how their current efforts may be less than transformative: "It really gives them a tool to take the blinders off. People often realize that values are key, but many other ones [transformative capacities] they are not doing at all." It was seen as "a language to guide strategic reflections, a way to identify actions to take to move in all three directions, and to situate different actions in each dimension" (FocG-FMS).

Many practitioners were very interested in how this framework could help them with the following needs: their impact assessment and reporting to garner support from funders and policy-makers, having an external point of view in addition to internal reflections, comparing assessment results with other organizations, as well as having a benchmark to analyze how advanced an SI initiative is in different dimensions (FocG-ECO, FocG-FMS, Int-RN). Many also expressed the need for developing more specific quantitative and qualitative indicators, based on the more generic elements in the 3D framework. It was suggested that these indicators should be tailored to their activities at different levels, depending on what they wish to focus on: from individual events, projects, and programs to an entire organization, network, or network of networks (FocG-ECO). A related suggestion was to develop more concrete rubrics or check-lists for each of the framework elements, so as to make it easier for practitioners to evaluate how well-developed their activities are in each area. Also, finding a way of merging those different levels of assessment into "some form of overarching indicators" was seen as a needed development of the framework to make it more useful (FocG-ECO).

While some practitioners appreciated the simplicity of the 3D perspective in general, the 3D framework was also found to be challenging to operationalize for assessment and goal-setting. This was due to the generic quality of the framework elements and the complexity of the number of elements and interactions to consider (Int-ECO, Int-GEN). When adapting the framework elements to the GO Movement context (see Appendix C), it became evident that they needed to be reduced in scope, simplified, and made specific to issues relevant for Green Offices. GEN and ECOLISE were still in the process of clarifying their strategic goals at the time of this study. Hence, they expressed that they first needed to clarify their goals internally, before the 3D framework could be operationalized into case-specific indicators. For them, the 3D framework was seen as more useful for refining goals and indicators they already articulated, instead of taking the framework as a starting point (Int-ECO, Int-GEN).

Some ambivalence was expressed about the usefulness of distinguishing transformative impact and transformative capacity among ECOLISE staff. Some perceived this as very useful, as it highlights the difference between what practitioners have achieved or seek to achieve (transformative impacts) versus that which is needed for them to be able to do so (transformative capacity). Yet, for others, 
"building transformative capacity and achieving impacts are so closely related as to almost make the distinction unhelpful" (PaOb-ECO). While acknowledging this inter-relatedness, we hope that the concretization of the framework helped to make the value of this distinction clearer. An interviewee from Fundación Mi Sangre also stated that the distinction between the diagnostic questions about impacts achieved and envisioned impacts helped to clarify capacity gaps: "what we need to nurture to ensure that we continue developing our impact" (Int-FMS).

A few practitioners also expressed a need to prioritize which of the elements in the 3D framework to focus on. A network leader from Transition Network expressed a perceived risk of such comprehensive frameworks to add to a sense of overwhelm, experienced by many social innovation practitioners: "many struggle with burn-out, given the complexity of working towards transformative change and shortages of time and money" (FocG-ECO). Instead of pointing out all the conditions one needs to think of, she suggested identifying the core strengths or niche of a network (e.g., in the domain of deepening) and focusing on building synergies with allied networks that have complementary strengths (e.g., widening). She stated the importance of finding the "reassurance of doing this work as part of a wider ecosystem" (FocG-ECO). When testing the framework as an evaluative tool, it was also suggested to prioritize a selection of key issues to address, as well as define actionable implications for strategic improvements (Int-FMS).

One suggestion for turning the framework into a "useful knowledge format" was to formulate a "pattern language" [71] (Int-ECO). This involves describing a set of patterns as recurring problem and solution statements that are applicable to many different contexts, as well as describing how they are connected to each other. This is an approach employed by ECOLISE [72], Transition Network (www. patterns.transitionresearchnetwork.org), and other social innovators (for example: group collaboration patterns: www.groupworksdeck.org; Sociocracy 3.0 patterns: www.patterns.sociocracy30.org) [73]. The transformative capacities presented in this article can offer an initial step in developing a pattern language that includes concrete practices for supporting capacity development and makes more explicit how these are connected.

\section{Discussion}

In this section we discuss our main findings and their significance for social innovation research and practice, reflect on the limitations of this study, and provide recommendations for future research.

In response to our first research question, we examined how transformative impact and capacity of social innovation networks can be identified and assessed, using a framework of three institutional dimensions: depth, width, and length. We applied and tested this 3D framework by identifying empirical examples to substantiate each of the framework elements, using diagnostic questions (Appendix B) that were developed based on the original framework. As the original types of transformative impacts were described rather generically, the examples we found make these more concrete and substantiate general themes in different case contexts. During the application it became clear that some of the original types of transformative capacities needed to be refined or complemented (as explained in the results section), to make them more concrete and representative of the empirical data we found.

While transformative capacities were so far described separately for each dimension, they were found to be highly inter-related in practice. We therefore also collected and coded data according to interactions among the three dimensions, which we present in Appendix D. As identifying interactions was not our main focus, these were, however, not studied in much detail. Hence, we only described them as general statements that could be derived from our data in a rather speculative way. More research would be required to substantiate these interactions in more detail, test their validity in various case contexts, and pay closer attention to synergies and tensions. See Figure 3 for the revised version of our original 3D framework [16] (see Figure 2 in Section 2), including the concretized elements and an indication of the interaction among capacities. 


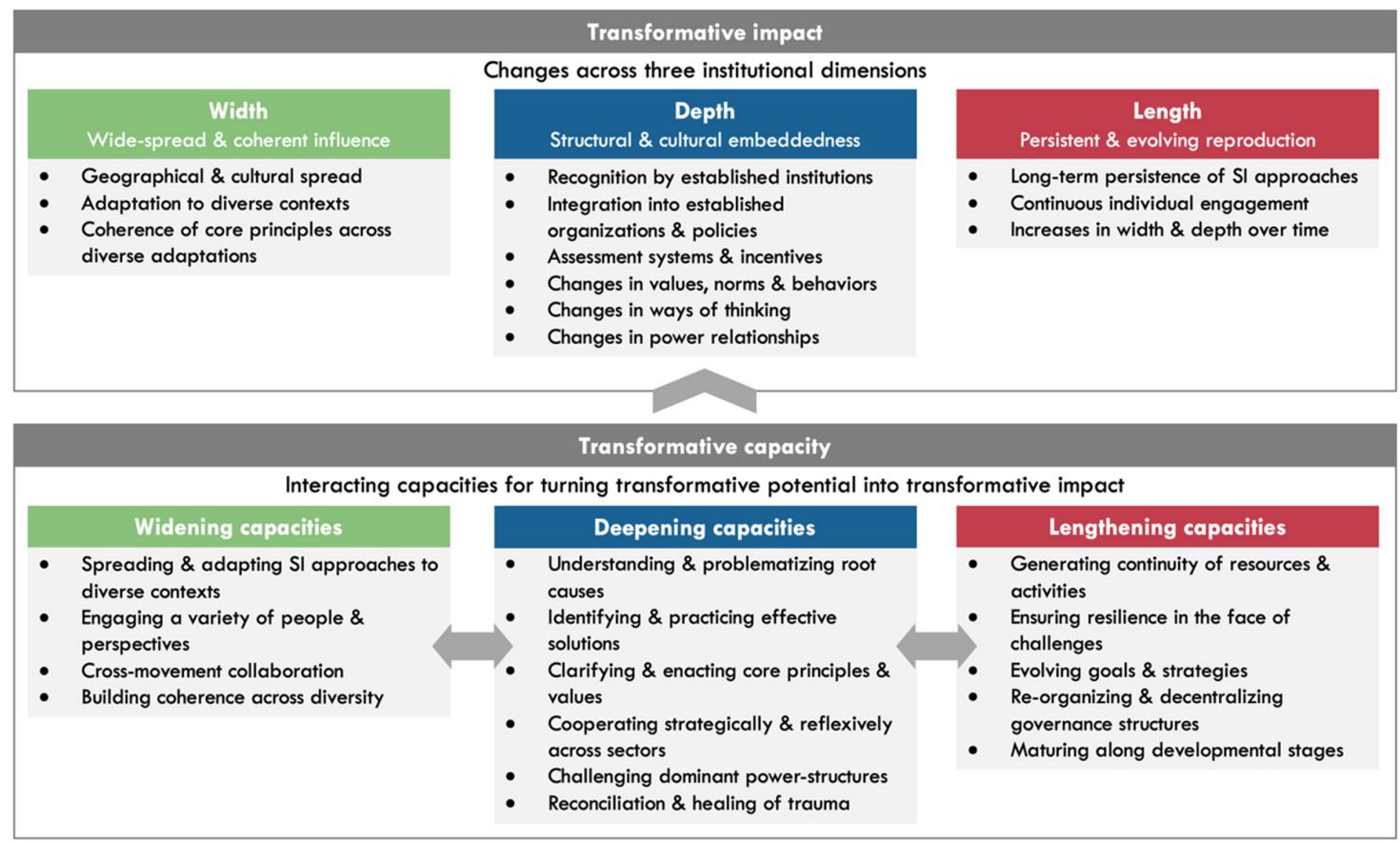

Figure 3. The revised framework elements of transformative impact and capacity, highlighting the interaction among capacities.

The results confirm that the 3D framework can be used for assessment purposes, while also indicating that it needs further development in this regard. The examples include general descriptions of the degree to which depth, width, and length impacts have been achieved and the extent to which capacities are more or less developed. However, the focus of this study was not to conduct a detailed and rigorous impact assessment. Rather, we sought to first test and evaluate whether the framework elements are indeed appropriate issues to focus on for an assessment and how they could be used for assessment purposes. It became clear in the application process and from practitioner feedback that a formal impact assessment would require the following further developments of the framework and the diagnostic questions (Appendix B) that were used in this study.

Firstly, developing more case-specific qualitative as well as quantitative indicators is needed to specify what to assess. As the framework elements are rather generic, indicators need to refer to specific social relations and related ways of doing, organizing, framing, and knowing (DOFK) that characterize a particular social innovation. This can be a challenging task, as units of analysis (i.e., what exactly to assess) are far from self-evident in the complex field of social innovation [22]. The process of developing case-specific indicators for the GO Movement (see Appendix C) and GEN and ECOLISE required (gaining) an in-depth understanding of the goals and issues specific to their case contexts.

Secondly, the definition of a clear assessment scope is required: that is, whether the ambition is to assess specific interventions (a program, event, etc.), a geographic focus region of a network, a network as a whole, or even an entire SI field, involving multiple networks and variations of related social innovations. A larger scope would require more capacity for conducting such an assessment.

Thirdly, the existing framework elements did not yet allow for assessing degrees of impacts achieved in a rigorous way. This would require the development of rubrics, ranging from lower to higher degrees of impacts for each dimension, with clear designation for each degree (i.e., on a Likert scale from one to five). We also found that it is important to differentiate between assessing the degree to which depth impacts occurred and the degree of depth of those changes. For instance, while Green Offices have achieved structural integration of sustainability in policies related to sustainable mobility or recycling, these changes are arguably not very transformative in terms of challenging underlying worldviews of the higher education system. Existing frameworks can be helpful to distinguish these 
degrees further, such as the leverage points framework of Meadows [74], or the distinction between incremental, reformative, and transformative change by Waddell $[20,75]$.

While a comparative analysis across cases was beyond the scope of this study, the 3D framework could be used for this purpose. Some overall differences can be observed between the cases. Green Offices are more structurally embedded, as they are integrated in universities; yet the kind of change promoted is mostly not (yet) very transformative: many focus on reducing the ecological footprint and emissions and giving more voice to students, more than challenging higher education and the socio-economic system at a deeper level. By comparison, oikos chapters are less structurally embedded than Green Offices; however, they promote deeper kinds of changes, by focusing on transforming economics and management education and promoting values-based leadership development, and sustainable finance. Ecovillages and Transition initiatives are generally less structurally embedded (with some exceptions of highly supportive governmental institutions), but more globally spread than the student-led sustainability cases. They also offer deeper solutions in terms of lived alternatives to a materialistic, individualistic, growth-based economy. Mi Sangre and Resonance Network promote deep cultural and systemic changes, though in a more geographically limited scope. Overall, the examples of transformative impact found in this study might be seen as still rather insignificant, considering the high degree of embeddedness, spread, and persistence of dominant institutions. Yet, they can also be regarded as examples of a multitude of TSI actors that are growing in recent years and may become more collectively transformative in the future [13], if they are able to deepen, widen, and lengthen their impacts. A more rigorous case comparison would require more detailed assessment of each case (see previous paragraphs). A challenge here could be that the indicators and rubrics used for assessing cases would need to be generic enough for meaningful cross-case comparison, yet also specific enough to be pertinent to unique case contexts. Possible avenues for finding such a balance between particularism and generalization include Qualitative Comparative Analysis [76] and multiplicity-oriented approaches [22,77].

In response to our second research question, we tested the recognizability and usefulness of the $3 \mathrm{D}$ framework in practice. In particular, drawing on practice experience and active engagement with cases helped to evaluate and strengthen the practical value of this framework. The 3D framework was generally perceived as meaningful and valuable for practitioners in social innovation networks. The conceptualization of specific elements of transformative impact and related capacities was seen as valuable, since identifying, assessing, and developing such capacities is a key priority for all cases. Compared to the frameworks and tools practitioners already use, having a conceptual language that focuses specifically on transformative change was considered as a valuable contribution. Also, most of the networks studied employ principle-based tools to assess, evaluate, and support capacity development of local initiatives (e.g., Transition Network's healthcheck, or GEN's Impact Assessment tool). While their tools are often based on essential conditions for local groups to be effective, they miss similar approaches that focus on the level of a network or movement as a whole. The 3D framework offers a comparable function for social innovation networks, more than local groups. The diagnostic questions and empirical examples we found can guide practitioners to be more reflective, strategic, and intentional in their efforts. The generally encouraging responses of practitioners speak to the potential of the framework to be further developed and more widely applied and tested in practice.

Our results contribute to the scientific literature on transformative social innovation and societal transitions $[13,23]$ in the following ways. In comparison to other typologies (see Loorbach [13]), we suggest (and tested in this study) that the three dimensions framework offers comprehensive, yet conceptually simple and intuitive meta categories to identify transformative impact and the capacities required to realize it. It also integrates the length dimension, which is missing or less explicit in other conceptualizations that are more focused on the width and depth dimensions. Transformative impacts and capacities of social innovation so far have not been described in detail in TSI theory and lack specificity in SI research more generally. Our results show how the 3D framework can be used 
to operationalize general notions about depth, scale, and persistence. The diagnostic questions and examples provided in this study can inform research efforts to identify, assess, and evaluate the impacts and capacities of social innovation networks. Furthermore, by focusing on institutional dimensions, the 3D framework offers a consistent framing of impact across a wide variety of cases in different institutional contexts or SI fields. While other frameworks mostly focus on describing the dynamics of scaling, trans-local diffusion, and changes in established systems, the 3D framework focuses on capacities [21,25-27] needed for SI actors to effectively contribute to transformative change. As patterns of effective practice, they therefore also have a prescriptive function for guiding social innovators to act more effectively [78]. By highlighting the importance of interactions among capacities, we further point to possible synergies and tensions among them (see Appendix D). This can guide strategic action by strengthening synergies, identifying high leverage interventions [79], and preventing or addressing possible trade-offs.

The following limitations of this study need to be mentioned. The qualitative case study approach did not allow for a more rigorous quantitative assessment of the cases. As explained above, this was not our priority, yet this would be valuable to test the framework more rigorously. The qualitative approach also entailed a limited number of cases that could be studied. A quantitative approach to test the framework elements in a larger set of cases would be useful in the future. Possible biases exist with regards to the embedded action research approach, considering the fact that the first author was conducting research on cases he himself is involved in as a practitioner. These include a potential overemphasis of the transformative impact of these cases and possible omissions of their weaknesses, even though care was taken to critically reflect upon implicit assumptions and personal attachments to the merit of the framework and to maintain a critical stance as much as possible. We deliberately opted to study multiple cases for refining and testing the framework in the light of evidence from diverse case contexts. However, a detailed comparative analysis across cases was not our intention. We studied some core cases with higher levels of detail, while studying others more generally, given time constraints. While the examples we found are case-specific, we expect that many of the general patterns (i.e., the refined framework elements) will be applicable across various social innovation contexts. However, the validity and applicability of the 3D framework deserves further investigation in a larger and more diverse set of cases, especially considering that the refinements and additions of the framework were based on a limited set of cases. Other case contexts might include the domains of public policy (e.g., participatory budgeting [80], or unconditional basic income [81]) and economics (e.g., the Economy for the Common Good [82], Doughnut economics [83], or integrated value delivery [84]).

Based on our results and the responses from practitioners, we offer the following recommendations for further research:

- Operationalize the 3D framework for impact assessment in different case contexts, by translating the generic capacities into case-specific goals and indicators. The examples and diagnostic questions provided here can guide this translation process. Defining rubrics could entail degrees of depth, width, and length (e.g., on a Likert scale from 1-5);

- Test if the generalized patterns of impact and capacity (and their interactions) are applicable across diverse cases and how they can be used for case comparison. This could be achieved through more in-depth longitudinal and comparative case research, including both qualitative and quantitative methods [39]. This might involve detailed impact assessments and analyses of the (interactions between) required capacities. Case comparison could involve mapping the results on spider diagrams;

- Translate the framework into a practice tool for various use applications, such as strategic goal setting, design of interventions, impact assessment, monitoring and evaluation, reflection and learning. In particular, using the capacities for principle-focused developmental evaluation [78] may be a promising application of the framework. Measuring the results of these applications for the cases could clarify the practical value and impact of using the tool: for instance, 
enhanced resourcing, changes in strategic activities, increased and more diverse engagement, etc. Furthermore, collecting feedback on the usability of the tool could help to design the form and process of using it in a way that suits the requirements of practitioners, so that they can and want to actually make use of the tool;

- Study how transformative capacities can be intentionally developed: Which learning processes are critical for developing transformative capacities among individuals, groups and networks? Specifically, through which roles and practices can network leadership support these? A pattern language $[71,73]$ could be developed by connecting these learning processes and network leadership practices to generalized patterns of capacities and their interactions.

Author Contributions: Conceptualization, T.S., J.d.K. and R.K.; Methodology, T.S., J.d.K. and R.K.; Formal Analysis, T.S.; Investigation, T.S.; Writing-Original Draft Preparation, T.S.; Writing-Review and Editing, J.d.K. and R.K.; Supervision, J.d.K. and R.K. All authors have read and agreed to the published version of the manuscript.

Funding: This research received no external funding but two of the authors were previously funded through the TRANSIT project.

Acknowledgments: The following case representatives and practitioners offered valuable support in co-organizing focus groups and offering feedback on the diagnostic questions, as well as the draft article: June Holley, Sadia Hassan, Anselm Grahl, Adrian Röbke and Tom Henfrey.

Conflicts of Interest: The authors declare no conflict of interest.

\section{Appendix A. Overview of Data Sources}

Table A1. Participant observation events.

\section{Case-cluster 1: Community-led initiatives (CLIs)}

- $\quad$ The 3-day annual ECOLISE General Assembly (in Croatia)

- A series of online meetings by ECOLISE to inform and engage its members in various collaborative activities, exchanges, and advocacy (www.ecolise.eu/ecolises-low-carbon-open-meeting-series-continues-in-2019-see-you-online/)

- Internal ECOLISE activity planning and strategy development meetings.

- Project meetings of ECOLISE's EU-funded "BLAST project" (Blended Adult Learning for the Socio-ecological Transition) (www.ecolise.eu/blast/)

- A 2-day workshop (in Belgium) of ECOLISE's community of practice for system transition facilitators, the Sustainable Communities Programme (www.ecolise.eu/sustainable-communities-programme)

- The annual GEN-Europe conference (in Italy)

- $\quad$ The Living Village Festival (in Netherlands), co-organized by GEN Netherlands (www.thelivingvillagefestival.org)

- A small local festival (in Germany) in the ecovillage Lebensgarten Steyerberg, one of the oldest ecovillages in Germany (www.lebensgarten.de/sommercamp/)

- The "Power of Community Online Summit" by GEN that broadcasted interviews among inspiring though-leaders and practitioners from GEN and like-minded innovators, while offering a Facebook group for exchange among participants (www.summit2019.ecovillage.org)

Case-cluster 2: Student-led initiatives (SLIs)

- The annual Student Sustainability Summit (in Manchester) of SOS-UK, one of the founding members of SOS (www.eventbrite.co.uk/e/nus-and-sos-uk-sustainability-summit-tickets-74400167905\#)

- The annual national sustainability conference (close to Berlin) of the German network "netzwerk n", which is a member of SOS and a partner of the GO Movement (www.netzwerk-n.org/anmeldung-konferenz-n-2019)

- The annual partner meeting of SOS members at an annual oikos community gathering in Switzerland, as part of their leadership program "LEAP" (www.oikos-international.org/programs/leadership-program-leap).

- Internal activity planning and strategy development meetings of the GO Movement and SOS 
Table A2. Document analysis.

Case-cluster 1: Community-led initiatives (CLIs)

- ECOLISE's Status Report [61], knowledge commons (www.wiki.ecolise.eu), and website (www.ecolise.eu), the strategic plan Communities for Future (in draft stage at the time of this study)

- GEN's website, annual report, program brochures, internal strategic documents

- Transition Network's video recordings from the project Municipalities in Transition (www.municipalitiesintransition.org/hot-topics)

- $\quad$ Case-study reports about GEN [85] and Transition Network [86]

Case-cluster 2: Student-led initiatives (SLIs)

- GO Movement website with good practice resources and the Green Office Model online course (www.greenofficemovement.org)

- $\quad$ Publication about the Green Office Model [56]

- $\quad$ oikos website (www.oikos-international.org)

Case-cluster 3: Citizen-led peace-building (CLP)

- Websites of Fundación Mi Sangre (www.fundacionmisangre.org) and Resonance Network (www.resonance-network.org)

Table A3. Focus groups.

\section{Case-cluster 1: Community-led initiatives (CLIs)}

- One focus group during an Open Space session at ECOLISE's General Assembly, with five participants from GEN and Transition Network.

- $\quad$ One focus group with 25 members of the Sustainable Communities Programme of ECOLISE during a 2-day workshop in Belgium (see Table A1), about strengths and shortcomings of the program, related to the 3D framework.

- Two online focus groups were organized in collaboration with three ECOLISE members, who were part of ECOLISE's "network health circle" as a shared reflection among ECOLISE member representatives on strategies for member engagement and needs for capacity development. In this case, the 3D framework was not used as a starting point for the reflection exercise, but as a means for clustering the results.

\section{Case-cluster 2: Student-led initiatives (SLIs)}

- In the role of GO Movement coordinator, the first author organized and facilitated two online focus groups (with 18-25 participants) as part of the Green Office Online Summit event that he organizes every semester. The three dimensions were used as an overall framing for the summit theme and program design. A form with GO Movement specific indicators (Appendix C) was used in combination with these online summits, where participants were invited to fill out the form in advance. The guiding question, plenary exploration, and parallel sessions revolved around deepening: changes in curriculum, operations, and governance; widening: community engagement and outreach, peer learning and partnerships; and lengthening: team transition, project management, alumni engagement, and organizational development.

- One focus group with five SOS member representatives about strengths and shortcomings, related to the 3D framework, during the annual meeting of SOS members at the LEAP meeting of oikos in Switzerland (see Table A1)

\section{Case-cluster 3: Citizen-led peace-building (CLP)}

- $\quad$ Two online focus groups with leaders from diverse networks, whereby the cases from case-cluster 3 (Fundación Mi Sangre and Resonance Network) were identified as offering rich examples and valuable feedback. These focus groups involved additional participants beyond the selected cases in a series of two 1.5-h calls, with on average 4-6 representatives of diverse social innovation networks. These were co-organized and facilitated with two network leaders who were eager to support the testing of the 3D framework. Sub-groups inquired into different dimensions of the framework elements simultaneously, using the break-out room function in the zoom software, while collaboratively noting their responses in a pre-structured shared google document. 
Table A4. Semi-structured interviews.

Case-cluster 1: Community-led initiatives (CLIs)

- $\quad$ Eight interviews with active members and staff of GEN and ECOLISE during participant observation events (see Table A1).

- $\quad$ Three interviews with staff from GEN and ECOLISE

Case-cluster 2: Student-led initiatives (SLIs)

- Twelve interviews in the form of "catch-up calls" that the first author conducted with Green Office coordinators as part of his GO Movement coordinator role. These calls involved discussing the achievements, goals and challenges of their teams. The GO Movement specific indicators were sent beforehand as optional preparation. The results from each of these meetings were aggregated in a central google document that is shared with all Green Offices as a collection of challenges and good practices.

Case-cluster 3: Citizen-led peace-building (CLP)

- $\quad$ One interview with two network coordinators from Fundación Mi Sangre. The diagnostic questions were used to structure this interview

- $\quad$ One interview with one network coordinator from Resonance Network. The diagnostic questions were used to structure this interview

\section{Appendix B. Diagnostic Questions}

Table A5. Diagnostic questions for transformative impacts.

\begin{tabular}{|c|c|}
\hline $\begin{array}{l}\text { Assessment } \\
\text { To what degree are these impacts achieved? } \\
\text { Are they gaining strength/dissipating? What are } \\
\text { examples/what evidence do you have, in which } \\
\text { specific contexts? Why are these significant? }\end{array}$ & $\begin{array}{l}\text { Evaluation } \\
\text { What impacts are still needed to become more } \\
\text { transformative, in which specific contexts, } \\
\text { and why? }\end{array}$ \\
\hline \multicolumn{2}{|c|}{ Depth impacts } \\
\hline $\begin{array}{l}\text { SI elements are structurally embedded in } \\
\text { constitutions, laws, policies, } \\
\text { incentive/accountability mechanisms, } \\
\text { organizational structures, codes of practice, } \\
\text { indicators of success, or decision-criteria. } \\
\text { - Which specific structural changes have been } \\
\text { achieved, in which contexts? }\end{array}$ & $\begin{array}{l}\text { - Which structural changes are still needed? } \\
\text { - Which structural limitations need to be } \\
\text { overcome (e.g., limiting land-use regulations, } \\
\text { perverse incentive structures, etc.)? }\end{array}$ \\
\hline $\begin{array}{l}\text { SI elements are culturally embedded in social } \\
\text { norms, mental models, beliefs, attitudes, behavioral } \\
\text { routines, informal agreements. } \\
\text { - Which specific cultural changes have } \\
\text { been achieved? }\end{array}$ & $\begin{array}{l}\text { Which cultural changes are still needed? } \\
\text { Which cultural limitations need to be } \\
\text { overcome (prejudices, misunderstandings, } \\
\text { limiting beliefs/worldviews, etc.)? }\end{array}$ \\
\hline
\end{tabular}


Table A5. Cont.

\section{Width impacts}

SI elements have been replicated in and adapted to diverse geographic, cultural, socio-economic, organizational (etc.) contexts.

- How many people and organizations are involved in practicing the SI models/elements (which ones specifically)?

- Which kind of people (ethnicity, gender, socio-economic status, functional role, values perspectives, etc.) and organizations (private, public, civil, academic) are generally most involved?

- In which countries more or less so?

SI elements are coherently enacted across diverse contexts and adaptations.

- Which are the essential elements (core narratives, principles, practices, etc.) that are recognizable across different cultural, organizational, socio-economic contexts,

- Which SI elements would need to be enacted and the adaptations of SI elements to those contexts?

- In which way do they differ/cohere in different contexts?

- Is adoption limited to certain contexts or population groups?

- How should/could they become adapted to more diverse contexts and inclusive of more diverse populations?

\section{Length impacts}

SI elements are reproduced persistently over time.

- To what degree and in which ways is continuity of SI elements maintained across generations of (roles and lifetimes) of members, leaders, advocates, decision-makers, supporting organizations, etc.?

SI elements are evolving and developing over time.

- Which changes have occurred in response to changing internal and external conditions, such as organizational maturity, learnings from mistakes or crises, political and environmental changes?

- Which are typical/potential threats that need to be overcome to ensure continuity?

- What are the conditions enabling persistence? Which conditions are needed to ensure stronger persistence?

Table A6. Diagnostic questions for transformative capacities.

\begin{tabular}{ll}
\hline $\begin{array}{l}\text { Assessment } \\
\text { To what extent does this capacity apply? In which } \\
\text { way does this apply? What are concrete examples? }\end{array}$ & $\begin{array}{l}\text { Evaluation } \\
\text { What further capacity development is needed? }\end{array}$ \\
\begin{tabular}{l} 
Why is this capacity important? \\
\multicolumn{1}{c}{ Deepening capacities } \\
way of developing these capacities?
\end{tabular} \\
\hline $\begin{array}{l}\text { SI actors are able to understand the workings and } \\
\text { problems of dominant institutions that are to } \\
\text { be transformed. }\end{array}$ \\
$\begin{array}{l}\text { What exactly do they need to understand } \\
\text { about dominant institutions, what is } \\
\text { problematic about them, and which ones } \\
\text { in particular? }\end{array}$ \\
$\begin{array}{l}\text { To what extent have they formed a } \\
\text { systemic narrative? }\end{array}$
\end{tabular}


Table A6. Cont.

\section{Deepening capacities}

SI actors are able to identify and enact a range of solution pathways for practically bringing about desired changes.

- What systemic changes are envisioned? What are examples of solutions needed?

- What practices and knowledge are needed to bring about the envisioned changes?

- What are examples of systemic solutions versus sustaining solutions?
- Which solutions and strategies seem to be working well, and why?

- Which new solutions are needed, or being developed?

- Which are not working, and why not?

- How do you determine which solutions are likely to be effective?

- $\quad$ Are the solutions promoted systemic/transformative enough, rather than just sustaining/reproducing dominant institutions? How may they become more transformative?

- In which ways may both sustaining and systemic solutions be needed and how can they go hand in hand?

SI actors are able to enact and maintain core values to promote the changes they wish to see.

- How clear are SI actors about their core values?

- Which values and related behaviors and relationships are essential to enact and maintain?

- Why and in which ways are these values core to promoting transformative change?
- What may be gaps between intentions and practice, i.e., what people say they stand for and what they actually do?

- What may be blind spots, i.e., which values may be overlooked?

- What are difficulties in enacting those values and why?
- Which need to be enacted more coherently?
SI actors are able to interact strategically with (representatives of) dominant institutions to advance their transformative goals, while being reflexive about how they may be reproducing or captured by dominant institutions.

- Which interactions are ongoing with representatives of dominant institutions (government, corporations, established NGOs, academia)?

- What have been the results of lobbying/advocacy efforts?
- How may interactions with dominant institutions compromise the integrity of core values and limit transformative potential?

- How may SI actors be (unconsciously) reproducing elements of dominant institutions that should be challenged?

- Which conditions/safeguards could help to prevent/solve this?

- In which way might lobby or advocacy efforts be needed?

- Why are these important?

\section{Widening capacities}

SI actors are able to spread and adapt SI elements to diverse contexts.

- Which SI elements are being spread and how are they being adapted?

- Which abilities are important for spreading and adapting those?

- Which context adaptations are important?
SI actors are able to engage a diversity of people as members, participants, ambassadors, allies.

- How are SI actors able to engage people from diverse backgrounds, perspectives, interests, values, etc.?
- What SI elements need to be spread and adapted more widely?

- Which capacities may be needed to spread and adapt to more diverse contexts?

- Which capacities may be needed to engage more diversity? 
Table A6. Cont.

\section{Widening capacities}

SI actors are able to maintain coherence of SI elements among diversity of adaptations and people involved.

- Considering how SI elements are being adapted, which SI elements are essential to be maintained across diversity?

- Which capacities are needed to do so?

SI actors are able to cooperate with other actors in the SI initiative, network, and the wider SI field.

- Which kinds of cooperation are important? Who are important allies?

- Which capacities are needed for making such cooperation effective?
- What may be needed for essential SI elements to not get compromised or lost due to diversity of adaptations or participants?

- How may coherence among diversity be generated, in service of more aligned collective action?

- Which capacities may be needed to cooperate better with allies from similar movements?

- Which capacities are needed to cooperate with actors who have different values or act in different movements or sectors?

\section{Lengthening capacities}

SI actors able to generate continuity of resources, values and activities.

- $\quad$ Consider the motivation, engagement and well-being of members, financial and physical resources, knowledge, stakeholder relationships, as well as initiatives, projects, events, and their results: how successfully are these being maintained over time?

- What enables this?
- Which resources and activities may be commonly lost or at risk of discontinuity?

- Which capacities may be needed to ensure stronger continuity of these?

SI actors are able to ensure resilience in the face of challenges that threaten their continuity.

- How successfully are they able to overcome threats like conflicts, burnout, trauma, crises, attacks, resistance? What enables this?

- Which capacities may still be needed for preparing or dealing with such challenges or threats?
SI actors are able to evolve core characteristics (SI elements, strategies, approaches) in response to changing conditions.

- How successfully are they able to learn from internal crises, difficulties, and mistakes or adapt to changes in the external social, ecological, or political environment?
- How could crises or difficulties be seen as invitations to evolve?

- How may current practices, perspectives, etc., need to respond to changing internal and external conditions?

- Which capacities may be needed to do so?
SI actors are able to mature along developmental stages of individuals, initiatives, organizations and networks.

- Which developmental stages are relevant in your SI contexts and at which stages are various SI actors and initiatives?
- $\quad$ At which stages may SI actors get stuck (for instance initiation) or lose momentum?

- What capacities may be needed to enable further maturation beyond initial stages? 


\section{Appendix C. GO Movement Specific Indicators}

\begin{tabular}{|c|c|c|}
\hline \multicolumn{2}{|c|}{ Impact focus } & $\begin{array}{l}\text { Goals } \\
\text { \& Activities }\end{array}$ \\
\hline \multirow{3}{*}{ 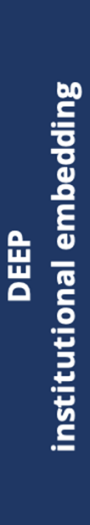 } & $\begin{array}{l}\text { Footprint } \\
\text { reductions }\end{array}$ & $\begin{array}{l}\text { radical reductions in the social and ecological footprint of our university's } \\
\text { operations: } \\
\text { circularity in operations, emission reductions, vegan \& vegetarian catering, eliminate } \\
\text { plastic waste }\end{array}$ \\
\hline & $\begin{array}{l}\text { curriculum } \\
\text { change }\end{array}$ & $\begin{array}{l}\text { integration of education for sustainability across disciplines: } \\
\text { curriculum inventory, new sustainability courses, applied research projects, support } \\
\text { for teachers }\end{array}$ \\
\hline & $\begin{array}{l}\text { governance } \\
\text { influence }\end{array}$ & $\begin{array}{l}\text { translation of sustainability as core priority into planning and decision- } \\
\qquad \text { making processes: } \\
\text { strategic goals, policies, action plans and reporting }\end{array}$ \\
\hline \multirow{3}{*}{ 岂 } & $\begin{array}{c}\text { partnership } \\
\text { collaborations }\end{array}$ & $\begin{array}{l}\text { collaboration among diverse partners for joint impact: } \\
\text { student organisations, academics, staff members and actors beyond campus } \\
\text { (municipalities, NGOS, schools, businesses, activists) }\end{array}$ \\
\hline & $\begin{array}{c}\text { reach } 8 \\
\text { engagement }\end{array}$ & $\begin{array}{l}\text { reaching diverse target groups to learn about and engage with } \\
\text { sustainability: } \\
\text { raising awareness and offering engagement opportunities to students \& staff with } \\
\text { diverse interests (beyond the "green bubble") }\end{array}$ \\
\hline & $\begin{array}{l}\text { learning } \\
\text { interactions }\end{array}$ & $\begin{array}{l}\text { interactions among people working for sustainability to learn from and } \\
\text { support each other: } \\
\text { virtual \& in-person knowledge sharing and capacity building }\end{array}$ \\
\hline \multirow{3}{*}{ 놀 } & $\begin{array}{c}\text { team } \\
\text { continuity }\end{array}$ & $\begin{array}{l}\text { safeguarding the continuity of knowledge, funding, projects and } \\
\text { stakeholder relations over time: } \\
\text { motivating work culture, effective team transitions, alumni advice, and } \\
\text { communicating results to satisfy funders }\end{array}$ \\
\hline & $\begin{array}{c}\text { organisational } \\
\text { development }\end{array}$ & $\begin{array}{l}\text { developing organisational capacity of the team over time: } \\
\text { evaluating and learning from past efforts, and innovating with new structures and } \\
\text { approaches }\end{array}$ \\
\hline & $\begin{array}{c}\text { alumni } \\
\text { engagement }\end{array}$ & $\begin{array}{l}\text { engagement of graduates as change-makers after their studies: } \\
\text { developing skills and values among students to become leaders of tomorrow }\end{array}$ \\
\hline
\end{tabular}

Figure A1. List of GO Movement specific indicators. The form that was used for members of Green Offices to self-assess their activities based on these indicators can be found here: www.bit.ly/GOHealth-Check. 


\section{Appendix D. Interactions among Transformative Capacities}

Table A7. Interactions among transformative capacities

\section{Deepening and widening interactions}

- $\quad$ Spreading SI approaches can support cultural and structural embedding, as SI initiatives gain more wide-spread support and recognition.

- $\quad$ Spreading geographically and engaging or cooperating with people who have different values or interests can make it difficult to maintain coherence across these differences. Core principles and values may be ignored, misunderstood or challenged, especially when cooperating with people who are "closer to the mainstream"

- $\quad$ Engaging a large number of people is often easier at more shallow levels of engagement (joining an awareness-raising event) and more challenging at deeper levels of engagement (deep inner reflection and personal transformation).

- $\quad$ Core principles support spreading and adapting SI approaches to diverse contexts. They also act as coherence generating mechanism across those diverse contexts (fidelity to core principles), which helps with enacting or embedding social innovation approaches more deeply in different contexts and prevents dilution of the transformative qualities of an SI initiative.

- A diversity of adaptations can also help to clarify or evolve core principles by synthesizing essential success ingredients across a diversity of experiments.

- Engaging a diversity of people can help to identify and address "blind-spots", such as unquestioned assumptions, unconscious attitudes, or behaviors that are re-producing dominant power relationships.

- Cross-movement collaboration can help spreading or developing more transformative approaches by integrating perspectives and approaches from different movements, as well as amplifying advocacy efforts for policy change through having a stronger shared voice.

- $\quad$ Principles and values also act as mechanism for building trust and alignment for cooperation across diverse movements.

- Challenging and embodying alternatives to power structures strengthens conditions for diversity and inclusivity, by overcoming systemic and psychological structures of privilege, exclusion and oppression (racism, classism, etc.).

\section{Deepening and lengthening interactions}

- Clear and strongly embedded principles can help to maintain and transfer those over time while avoiding co-optation. Yet, principles and values may also need to evolve in response to learnings or changing context conditions.

- The legitimacy and capacity for deeper influence at policy levels tend to develop at later stages of maturity, often through formation of networks at higher levels of scale.

\section{Widening and lengthening interactions}

- Wider spread can strengthen the resilience of SI initiatives, as they are less dependent on the success of central individuals or groups and can draw on good practice examples from diverse contexts to address their challenges.

- $\quad$ Coherence helps to prevent conflicts due to divergent perspectives, which can threaten persistence. Shared understanding of core principles, narratives and strategies supports collaboration and continuity.

- Coherence enables maturation, as diverse actors have a shared basis of understanding on which to develop new goals and strategies that are aligned with shared principles, instead of creating fragmentation. 
Table A7. Cont.

\section{Interactions across all three dimensions}

- Cross-movement collaboration, strategic advocacy, and cross-sector cooperation can create supportive institutional frameworks. These can facilitate the spread and the continuity or maturation of SI approaches, due to favorable incentives, perceived legitimacy, funding streams, or legal frameworks.

- The capacity (or failure of) SI initiatives to address power structures can positively or negatively affect the inclusivity or accessibility for diverse populations, as well as their legitimacy, resource-base or member involvement to continue operating.

- $\quad$ Overcoming deep-seated trauma (judgements, wounds, or resentments) can allow for moving beyond recurring cycles of violence or patterns of fragmentation to adopt new goals and strategies, while enabling wider engagement and enhanced collaboration across diversity.

- Evolving goals and strategies may be needed to reach more (diverse) people and to achieve deeper structural and cultural change.

- Developing decentral organizational structures can allow engagement and collaboration of more (diverse) people and enable more autonomous decision-making that is adaptative to context-specific needs, while embodying alternatives to hierarchical power structures.

- Offering engagement and support options for individuals and groups at different levels of depth and stages of their individual or cultural development can enable wider spread and more diverse engagement, as people with different needs and interests are being addressed. Some cases offer "pathways" of engagement options, etc., that build upon each other so that individuals and groups can mature and deepen over time.

\section{References}

1. O'Brien, K.L. Climate change and social transformations: Is it time for a quantum leap? Wiley Interdiscip. Rev. Clim. Change 2016, 7, 618-626. [CrossRef]

2. O'Brien, K.; Selboe, E. Social Transformation. In The Adaptive Challenge of Climate Change; O'Brien, K., Selboe, E., Eds.; Cambridge University Press: Cambridge, UK, 2015; pp. 311-324. ISBN 978-1-139-14938-9.

3. Olsson, P.; Moore, M.-L.; Westley, F.R.; McCarthy, D.D.P. The concept of the anthropocene as a game-changer: A new context for social innovation and transformations to sustainability. Ecol. Soc. 2017, 22, 31. [CrossRef]

4. Fazey, I.; Schäpke, N.; Caniglia, G.; Patterson, J.; Hultman, J.; van Mierlo, B.; Säwe, F.; Wiek, A.; Wittmayer, J.; Aldunce, P.; et al. Ten essentials for action-oriented and second order energy transitions, transformations and climate change research. Energy Res. Soc. Sci. 2018, 40, 54-70. [CrossRef]

5. Hoegh-Guldberg, O.; Jacob, D.; Bindi, M.; Brown, S.; Camilloni, I.; Diedhiou, A.; Djalante, R.; Ebi, K.; Engelbrecht, F.; Guiot, J.; et al. Impacts of $1.5^{\circ} \mathrm{C}$ Global Warming on Natural and Human Systems. Available online: https://www.ipcc.ch/sr15/chapter/chapter-3/ (accessed on 1 March 2019).

6. Boillat, S.; Speranza, I.C. IPBES Global Assessment Report on Biodiversity and Ecosystem Services. Chapter 3. Assessing Progress Towards Meeting Major International Objectives Related to Nature and Nature's Contributions to People; IPBES: Bonn, Germany, 2019; Available online: https://ipbes.net/sites/default/files/ipbes_global_ assessment_chapter_3_unedited_31may.pdf (accessed on 1 March 2019).

7. Díaz, S.; Settele, J.; Brondízio, E.; Ngo, H.; Guèze, M.; Agard, J.; Arneth, A.; Balvanera, P.; Brauman, K.; Butchart, S.; et al. Summary for Policymakers of the Global Assessment Report on Biodiversity and Ecosystem Services of the Intergovernmental Science-Policy Platform on Biodiversity and Ecosystem Services; IPBES: Bonn, Germany, 2019; Available online: https://zenodo.org/record/3553579 (accessed on 1 March 2019).

8. European Commission; Bureau of European Policy Advisers (BEPA). Empowering People, Driving Change: Social Innovation in the European Union; EUR-OP: Luxembourg, 2011; ISBN 978-92-79-19275-3. Available online: https://op.europa.eu/en/publication-detail/-/publication/4e23d6b8-5c0c-4d38-bd9d-3a202e6f1e81/ language-en/format-PDF/source-31731269 (accessed on 1 March 2019).

9. Avelino, F.; Wittmayer, J.M.; Pel, B.; Weaver, P.; Dumitru, A.; Haxeltine, A.; Kemp, R.; Jørgensen, M.S.; Bauler, T.; Ruijsink, S.; et al. Transformative social innovation and (dis)empowerment. Technol. Forecast. Soc. Change 2019, 145, 195-206. [CrossRef]

10. Pel, B. Trojan horses in transitions: A dialectical perspective on innovation 'capture'. J. Environ. Policy Plan. 2016, 18, 673-691. [CrossRef] 
11. Smith, W.K.; Erez, M.; Jarvenpaa, S.; Lewis, M.W.; Tracey, P. Adding Complexity to Theories of Paradox, Tensions, and Dualities of Innovation and Change: Introduction to Organization Studies Special Issue on Paradox, Tensions, and Dualities of Innovation and Change. Organ. Stud. 2017, 38, 303-317. [CrossRef]

12. Pel, B.; Kemp, R. Between innovation and restoration; towards a critical-historicizing understanding of social innovation niches. Technol. Anal. Strateg. Manag. 2020, 1-13. [CrossRef]

13. Loorbach, D.; Wittmayer, J.; Avelino, F.; von Wirth, T.; Frantzeskaki, N. Transformative innovation and translocal diffusion. Environ. Innov. Soc. Transit. 2020, 35, 251-260. [CrossRef]

14. Haxeltine, A.; Pel, B.; Dumitru, A.; Avelino, F.; Kemp, R.; Bauler, T.; Kunze, I.; Dorland, J.; Wittmayer, J.; Jørgensen, M.S. Towards a TSI Theory: A Relational Framework and 12 Propositions. Available online: http:/www.transitsocialinnovation.eu/content/original/Book\%20covers/Local\%20PDFs/ 286a\%20TRANSIT_WorkingPaper_TowardsTSItheory\%20AH161217.pdf (accessed on 1 March 2019).

15. Wittmayer, J.M.; Backhaus, J.; Avelino, F.; Pel, B.; Strasser, T.; Kunze, I.; Zuijderwijk, L. Narratives of change: How social innovation initiatives construct societal transformation. Futures 2019, 112, 102433. [CrossRef]

16. Strasser, T.; de Kraker, J.; Kemp, R. Developing the Transformative Capacity of Social Innovation through Learning: A Conceptual Framework and Research Agenda for the Roles of Network Leadership. Sustainability 2019, 11, 1304. [CrossRef]

17. Feola, G. Societal transformation in response to global environmental change: A review of emerging concepts. Ambio 2015, 44, 376-390. [CrossRef] [PubMed]

18. Haxeltine, A.; Pel, B.; Dumitru, A.; Kemp, R.; Avelino, F.; Jørgensen, M.S.; Wittmayer, J.; Kunze, I.; Dorland, J.; Bauler, T. Consolidated Version of Transformative Social Innovation Theory, Deliverable No. D3.4. Available online: http://www.transitsocialinnovation.eu/content/original/Book\%20covers/Local\%20PDFs/272\% 20TRANSIT\%20D3.4\%20Consolidated\%20version\%20of\%20TSI\%20theory.pdf (accessed on 1 March 2020).

19. Polanyi, K. The Great Transformation: The Political and Economic Origins of Our Time; Beacon Press: Boston, MA, USA, 2001; ISBN 978-0-8070-5642-4.

20. Waddell, S.; Waddock, S.; Cornell, S.; Dentoni, D.; McLachlan, M.; Meszoely, G. Large systems change: An emerging field of transformation and transitions. J. Corp. Citizsh. 2015, 58, 5-30. [CrossRef]

21. Wigboldus, S.; Brouwers, J.; Snel, H. How a Strategic Scoping Canvas Can Facilitate Collaboration between Partners in Sustainability Transitions. Sustainability 2019, 12, 168. [CrossRef]

22. Pel, B.; Dorland, J.; Wittmayer, J.; Jørgensen, M. Detecting social innovation agency: Methodological reflections on units of analysis in dispersed transformation processes. Eur. Public Soc. Innov. Rev. 2017, 2, 110-126. [CrossRef]

23. Avelino, F.; Dumitru, A.; Cipolla, C.; Kunze, I.; Wittmayer, J. Translocal empowerment in transformative social innovation networks. Eur. Plan. Stud. 2019, 1-23. [CrossRef]

24. Jørgensen, M.S.; Avelino, F.; Dorland, J.; Rach, S.; Wittmayer, J. Synthesis across Social Innovation Case Studies: Deliverable 4.4. Available online: http://www.transitsocialinnovation.eu/content/original/Book\% 20covers/Local\%20PDFs/207\%20TRANSIT_D4.4_Synthesis\%20Report\%20about\%20all\%20in-depth\% 20case\%20studies.pdf (accessed on 1 March 2019).

25. Hölscher, K.; Loorbach, D.A. Transforming Urban Climate Governance: Capacities for Transformative Climate Governance. Ph.D. Thesis, Erasmus University Rotterdam, Rotterdam, The Netherlands, 2019.

26. Moore, M.-L.; Olsson, P.; Nilsson, W.; Rose, L.; Westley, F.R. Navigating emergence and system reflexivity as key transformative capacities: Experiences from a global fellowship program. Ecol. Soc. 2018, 23. [CrossRef]

27. Castán Broto, V.; Trencher, G.; Iwaszuk, E.; Westman, L. Transformative capacity and local action for urban sustainability. Ambio 2019, 48, 449-462. [CrossRef] [PubMed]

28. Weber, E.P.; Khademian, A.M. Wicked problems, knowledge challenges, and collaborative capacity builders in network settings. Public Adm. Rev. 2008, 68, 334-349. [CrossRef]

29. Ehnert, F.; Frantzeskaki, N.; Barnes, J.; Borgström, S.; Gorissen, L.; Kern, F.; Strenchock, L.; Egermann, M. The acceleration of urban sustainability transitions: A comparison of Brighton, Budapest, Dresden, Genk, and Stockholm. Sustainability 2018, 10, 612. [CrossRef]

30. Frantzeskaki, N.; Borgström, S.; Gorissen, L.; Egermann, M.; Ehnert, F. Nature-based solutions accelerating urban sustainability transitions in cities: Lessons from Dresden, Genk and Stockholm cities. In Nature-Based Solutions to Climate Change Adaptation in Urban Areas: Linkages between Science, Policy and Practice; Kabisch, N., Korn, H., Stadler, J., Bonn, A., Eds.; Springer International Publishing: Cham, Switzerland, 2017; pp. 65-88. ISBN 978-3-319-56091-5. 
31. Gorissen, L.; Spira, F.; Meynaerts, E.; Valkering, P.; Frantzeskaki, N. Moving towards systemic change? Investigating acceleration dynamics of urban sustainability transitions in the Belgian city of Genk. J. Clean. Prod. 2018, 173, 171-185. [CrossRef]

32. Van den Bosch, S. Transition Experiments: Exploring Societal Changes Towards Sustainability. Ph.D. Thesis, Erasmus University Rotterdam, Rotterdam, The Netherlands, September 2010.

33. Raven, R.; Van den Bosch, S.; Weterings, R. Strategic niche management and transition experiments. In Proceedings of the 4th Dubrovnik Conference on Sustainable Development of Energy Water and Environment Systems, Dubrovnik, Croatia, 4-8 June 2007; pp. 4-8.

34. Seyfang, G.; Haxeltine, A. Growing grassroots innovations: Exploring the role of community-based initiatives in governing sustainable energy transitions. Environ. Plan. C Gov. Policy 2012. [CrossRef]

35. Smith, A. Translating sustainabilities between green niches and socio-technical regimes. Technol. Anal. Strateg. Manag. 2007, 19, 427-450. [CrossRef]

36. Von Wirth, T.; Fuenfschilling, L.; Frantzeskaki, N.; Coenen, L. Impacts of urban living labs on sustainability transitions: Mechanisms and strategies for systemic change through experimentation. Eur. Plan. Stud. 2019, 27, 229-257. [CrossRef]

37. Smith, A.; Raven, R. What is protective space? Reconsidering niches in transitions to sustainability. Res. Policy 2012, 41, 1025-1036. [CrossRef]

38. Moore, M.-L.; Riddell, D.; Vocisano, D. Scaling out, scaling up, scaling deep: Strategies of non-profits in advancing systemic social innovation. J. Corp. Citizsh. 2015, 58, 67-84. [CrossRef]

39. Kaletka, C.; Schröder, A. A global mapping of social innovations: Challenges of a theory driven methodology. Eur. Public Soc. Innov. Rev. 2017, 2, 78-92. [CrossRef]

40. Fligstein, N.; McAdam, D.D. Toward a general theory of strategic action fields. Sociol. Theory 2011, $29,1-26$. [CrossRef]

41. Haxeltine, A.; Pel, B.; Wittmayer, J.; Dumitru, A.; Kemp, R.; Avelino, F. Building a middle-range theory of Transformative Social Innovation; theoretical pitfalls and methodological responses. Eur. Public Soc. Innov. Rev. 2017, 2, 59-77. [CrossRef]

42. Wittmayer, J.; Pel, B.; Tom, B.; Avelino, F. Editorial synthesis: Methodological challenges in social innovation research. Eur. Public Soc. Innov. Rev. 2017, 2, 1-16. [CrossRef]

43. Denscombe, M. The Good Research Guide: For Small-Scale Social Research Projects, 2nd ed.; Open University Press: Maidenhead, UK, 2003; ISBN 978-0-335-21303-0.

44. Yin, R.K. Case Study Research: Design and Methods Sage; Sage Publications: Thousand Oaks, CA, USA, 2003; ISBN 0-7619-2552-X.

45. Patton, M.Q. Qualitative Research E Evaluation Methods: Integrating Theory and Practice; Sage publications: Thousand Oaks, CA, USA, 2014; ISBN 1-4833-0145-1.

46. Ragin, C.C.; Amoroso, L.M. Constructing Social Research: The Unity and Diversity of Method; Pine Forge Press: Thousand Oaks, CA, USA, 2011; ISBN 1-4129-6018-5.

47. Reason, P.; Bradbury, H. Handbook of Action Research: Participative Inquiry and Practice; Sage Publications: Thousand Oaks, CA, USA, 2001; ISBN 978-0-7619-6645-6.

48. Herr, K.; Anderson, G.L. The Action Research Dissertation: A Guide for Students and Faculty; SAGE Publications: Thousand Oaks, CA, USA, 2014; ISBN 978-1-4833-5811-6.

49. Nielsen, K.A.; Svensson, L. Action Research and Interactive Research: Beyond Practice and Theory; Shaker Publishing: Maastricht, The Netherlands, 2006; ISBN 978-90-423-0289-1.

50. Lindberg, M.; Hylander, J.P. Boundary dimensions of social innovation: Negotiating conflicts and compatibilities when developing a national agenda. Innov. Eur. J. Soc. Sci. Res. 2017, 30, 168-181. [CrossRef]

51. Jessop, B.; Moulaert, F.; Hulgård, L.; Hamdouch, A. Social innovation research: A new stage in innovation analysis. In The International Handbook on Social Innovation: Collective Action, Social Learning and Transdisciplinary Research; Edward Elgar: Cheltenham, UK, 2013; pp. 110-130. ISBN 978-1-84980-998-6.

52. Moulaert, F.; Van Dyck, B. Framing social innovation research: A sociology of knowledge perspective. In The International Handbook on Social Innovation: Collective Action, Social Learning and Transdisciplinary Research; Edward Elgar: Cheltenham, UK, 2013; ISBN 978-1-84980-998-6.

53. Henfrey, T.; Brangwyn, B. Transition Research Primer. Available online: http://www.transitionresearchnetwork. org/uploads/1/2/7/3/12737251/transition_research_primer.pdf (accessed on 1 March 2020). 
54. Patten, M.L.; Newhart, M. Understanding Research Methods: An Overview of the Essentials; Taylor \& Francis: Abingdon, UK, 2017; ISBN 978-1-351-81738-7.

55. Saldana, J. The Coding Manual for Qualitative Researchers; Sage Publications: Thousand Oaks, CA, USA, 2015; ISBN 978-1-4739-4359-9.

56. Filho, W.L.; Will, M.; Salvia, A.L.; Adomßent, M.; Grahl, A.; Spira, F. The role of green and sustainability offices in fostering sustainability efforts at higher education institutions. J. Clean. Prod. 2019, 232, 1394-1401. [CrossRef]

57. Avelino, F. Power in sustainability transitions: Analysing power and (dis)empowerment in transformative change towards sustainability: Power in sustainability transitions. Environ. Policy Gov. 2017, 27, 505-520. [CrossRef]

58. Avelino, F.; Wittmayer, J.M. Shifting power relations in sustainability transitions: A multi-actor perspective. J. Environ. Policy Plan. 2016, 18, 628-649. [CrossRef]

59. Wahl, D. Designing Regenerative Cultures; Triarchy Press: Bridport, UK, 2016; ISBN 978-1-909470-78-1.

60. Eisenstein, C. The More Beautiful World our Hearts Know is Possible; North Atlantic Books: Berkeley, CA, USA, 2013; Volume 2, ISBN 1-58394-725-6.

61. Penha-Lopes, G.; Henfrey, T. Reshaping the Future: How Communities are Catalysing Social, Economic and Ecological Transformation in Europe. The First Status Report on Community-Led Action on Sustainability and Climate Change; ECOLISE: Brussels, Belgium, 2019; Available online: https://www.ecolise.eu/wp-content/uploads/2016/02/Executive-SummaryStatus-Report-on-Community-led-Action-on-Sustainability-and-Climate-Change-in-Europe-2019-.pdf (accessed on 1 March 2020).

62. Okun, T. The Characteristics of White Supremacy Culture. Available online: https://www.dismantlingracism. org/uploads/4/3/5/7/43579015/okun_-_white_sup_culture.pdf (accessed on 1 March 2020).

63. Holley, J. Dismantling Racism Is the Place to Start in Creating System Shifting Networks. Available online: https://networkweaver.com/dismantling-racism-is-the-place-to-start-in-creating-system-shiftingnetworks/ (accessed on 19 March 2020).

64. Heidelberg, B.M. Evaluating equity: Assessing diversity efforts through a social justice lens. Cult. Trends 2019, 28, 391-403. [CrossRef]

65. Transition Network. Inner Transition. Available online: https://transitionnetwork.org/about-the-movement/ what-is-transition/inner/ (accessed on 14 May 2020).

66. Berzonsky, C.L.; Moser, S.C. Becoming homo sapiens sapiens: Mapping the psycho-cultural transformation in the anthropocene. Anthropocene 2017, 20, 15-23. [CrossRef]

67. Marino, E.; Ribot, J. Special issue introduction: Adding insult to injury: Climate change and the inequities of climate intervention. Glob. Environ. Change 2012, 22, 323-328. [CrossRef]

68. Roberts, J.T.; Parks, B. A Climate of Injustice: Global Inequality, North-South Politics, and Climate Policy; MIT Press: Cambridge, MA, USA, 2006; ISBN 0-262-26441-2.

69. Woodbury, Z. Climate trauma: Toward a new taxonomy of trauma. Ecopsychology 2019, 11, 1-8. [CrossRef]

70. Beamish, T.D.; Luebbers, A.J. Alliance building across social movements: Bridging difference in a peace and justice coalition. Soc. Probl. 2009, 56, 647-676. [CrossRef]

71. Alexander, C. A Pattern Language: Towns, Buildings, Construction; Oxford University Press: Oxford, UK, 1977; ISBN 0-19-972653-1.

72. ECOLISE Wiki: A Knowledge Commons for Community-Led Action on Sustainability and Climate Change. Available online: http://wiki.ecolise.eu/index.php?title=EcoliseWiki:A_knowledge_commons_for_ community-led_action_on_sustainability_and_climate_change (accessed on 27 March 2020).

73. De Moor, A. Creativity meets rationale: Collaboration patterns for social innovation. In Creativity and Rationale; Carroll, J.M., Ed.; Springer: London, UK, 2013; Volume 20, pp. 377-404. ISBN 978-1-4471-4110-5.

74. Meadows, D.H. Leverage Points: Places to Intervene in a System; The Sustainability Institute: Hartland, VT, USA, 1999; Available online: http://cp.art.cmu.edu/wp-content/uploads/2014/12/8BD4EC4B-DAC3-4B3A8177-7848F3687688.pdf (accessed on 1 December 2019).

75. Dentoni, D.; Waddell, S.; Waddock, S. Pathways of transformation in global food and agricultural systems: Implications from a large systems change theory perspective. Curr. Opin. Environ. Sustain. 2017, 29, 8-13. [CrossRef]

76. Byrne, D. Complexity, configurations and cases. Theory Cult. Soc. 2005, 22, 95-111. [CrossRef] 
77. Pel, B. Intersections in system innovation: A nested-case methodology to study co-evolving innovation journeys. Technol. Anal. Strateg. Manag. 2014, 26, 307-320. [CrossRef]

78. Patton, M.Q. Principles-Focused Evaluation: The GUIDE; Guilford Publications: New York, NY, USA, 2017; ISBN 978-1-4625-3182-0.

79. Abson, D.J.; Fischer, J.; Leventon, J.; Newig, J.; Schomerus, T.; Vilsmaier, U.; von Wehrden, H.; Abernethy, P.; Ives, C.D.; Jager, N.W.; et al. Leverage points for sustainability transformation. Ambio 2017, 46, 30-39. [CrossRef] [PubMed]

80. Cipolla, C.; Afonso, R.; Wittmayer, J.; Serpa, B.; Rach, S. WP 4 Case Study Report: Participatory Budgeting; TRANSIT: EU SSH.2013.3.2-1 Grant Agreement No. 613169; 2016; Available online: http://www.transitsocialinnovation.eu/content/ original/Book\%20covers/Local\%20PDFs/196\%202016-01-20\%20Participatory\%20Budgeting\%20Final\%20Report.pdf (accessed on 1 March 2019).

81. Backhaus, J.; Pel, B. WP4 Case Study Report: BIEN and the Basic Income; TRANSIT: EU SSH.2013.3.2-1 Grant Agreement No. 613169; 2017; Available online: http://www.transitsocialinnovation.eu/resource-hub/wp4case-study-report-bien-and-the-basic-income (accessed on 1 March 2019).

82. Felber, C. Change Everything: Creating an Economy for the Common Good; Zed Books Ltd.: London, UK, 2019; ISBN 1-78699-747-9.

83. Raworth, K. Doughnut Economics: Seven Ways to Think Like a 21st-Century Economist; Chelsea Green Publishing: White River Junction, VT, USA, 2017; ISBN 1-60358-674-1.

84. Visser, W. Creating integrated value through sustainable innovation: A conceptual framework. In Sustainable Business Models: Principles, Promise, and Practice; Moratis, L., Melissen, F., Idowu, S.O., Eds.; Springer International Publishing: Cham, Switzerland, 2018; pp. 129-150. ISBN 978-3-319-73503-0.

85. Kunze, I.; Avelino, F. Social Innovation and the Global Ecovillage Network. Research Report; TRANSIT: EU SSH.2013.3.2-1 Grant Agreement No. 613169; 2015; Available online: http://www.transitsocialinnovation. eu/resource-hub/global-ecovillage-network-gen (accessed on 1 March 2019).

86. Longhurst, N.; Pataki, G. WP4 Case Study Report: The Transition Movement; TRANSIT: EU SSH.2013.3.2-1 Grant Agreement No. 613169; 2015; Available online: http://www.transitsocialinnovation.eu/resource-hub/ transition-towns (accessed on 1 March 2019).

(C) 2020 by the authors. Licensee MDPI, Basel, Switzerland. This article is an open access article distributed under the terms and conditions of the Creative Commons Attribution (CC BY) license (http://creativecommons.org/licenses/by/4.0/). 